\title{
GIOVANNI DE FORESTA, DEPUTATO ALLA CAMERA SUBALPINA E MINISTRO DELLA GIUSTIZIA (1850-1859)
}

\author{
GIOVANNI DE FORESTA, MEMBER OF THE SUPALPINE PARLIAMENT \\ AND MINISTER OF JUSTICE (1850-1859)
}

\author{
Mario Riberi \\ Università degli Studi di Torino
}

\begin{abstract}
English: The Nice-born jurist Giovanni de Foresta is a little-known and littlestudied figure, despite his considerable contribution to the cause of the unity of Italy. A supporter of Cavour, he sat in the Subalpine Chamber for two legislatures, the IV and the V, and held two important government's positions: he was Minister of Grace and Justice in the first D'Azeglio government and in the second Cavour government, around the time in that the laws "Siccardi" were in force. My paper aims to explain how De Foresta tried to develop his draft bills of renewal of justice and the judicial system during these two ministerial mandates. First of all, the bill, concerning some restrictions on the freedom of the press, which was converted into law on 26 February 1852: the ensuing parliamentary debate led to the fracture of the right and gave rise to the alliance between Rattazzi and Cavour for the formation of a progressive government. Later is illustrated the work carried out by De Foresta in the years 1855-59 for the updating of the codification of the Kingdom of Sardinia through the elaboration of a new code of civil procedure and the revision of the penal codes, which in 1860 replaced the Albertine ones. Finally, is presented the contribution given in 1858 by De Foresta to the alliance with France deemed indispensable by Cavour to achieve the unity of Italy - when as Minister of Justice, to meet the requests of the French government, pushed through Parliament the laws on sanctions to be imposed on conspirators against foreign heads of state.
\end{abstract}

Keywords: Giovanni de Foresta; Cavour; Parliament; Freedom of the press; Codification

Abstract Italiano: II giurista nizzardo Giovanni de Foresta è un personaggio poco noto e pochissimo studiato, nonostante il suo notevole apporto dato alla causa dell'unità d'Italia. Sostenitore di Cavour, sedette alla Camera subalpina per due legislature, la IV e la V, e rivesti due importanti incarichi di governo: fu ministro di Grazia e Giustizia sia nel primo governo D’Azeglio sia nel secondo governo Cavour, nel periodo di entrata in vigore delle leggi Siccardi. Oggetto di questo articolo sono i progetti elaborati da De Foresta durante questi due incarichi ministeriali. Innanzitutto il progetto che si tradusse nella legge del 26 febbraio 1852 sull'introduzione di misure restrittive della libertà di stampa: il dibattito parlamentare che ne seguì portò alla frattura della destra e alla stagione del "connubio" Cavour-Rattazzi. Successivamente viene illustrata l'opera svolta da De Foresta negli anni 1855-59 per il rinnovamento della codificazione del Regno di Sardegna attraverso

* Italian Review of Legal History, 7 (2021), n. 7, pagg. 199-255

* https://riviste.unimi.it/index.php/irlh/index

* ISSN 2464-8914 - DOI 10.54103/2464-8914/16889. Articolo pubblicato sotto Licenza CC-BY. 
l'apertura di un cantiere sia per l'elaborazione del codice di procedura civile sia per la revisione dei codici penali, che nel 1860 sostituirono quelli albertini. È infine presentato il contributo dato nel 1858 da De Foresta all'alleanza con la Francia, ritenuta indispensabile da Cavour per realizzare l'unità d'Italia, quando il Guardasigilli, per venire incontro alle richieste del governo francese, fece approvare dal Parlamento subalpino la legge sulle sanzioni da infliggere ai cospiratori contro i capi di stato stranieri.

Parole chiave: Giovanni de Foresta; Cavour; Parlamento; Libertà di stampa; Codificazione

Sommario: 1. Cenni biografici e contesto storico-giuridico. - 2. Gli interventi di De Foresta alla Camera subalpina. - 3. L'approvazione della nuova legge sulla stampa del 26 febbraio 1852 e le sue conseguenze politiche. - 4. Il contributo di De Foresta al rinnovamento della codificazione del Regno di Sardegna (1853-1859). - 4.1. L'apertura del cantiere per l'elaborazione di un nuovo Codice di procedura civile. -4.2. La revisione del Codice penale. -5 . De Foresta e l'approvazione della cosiddetta legge sui conventi. - 6. La legge sulla repressione dei reati di apologia dell'assassinio politico e di cospirazione contro la vita dei capi di stato esteri. - 7. Conclusione.

\section{Cenni biografici e contesto storico-giuridico}

Jean (Giovanni) de Foresta, nato nel 1799 a Villefranche sur Mer da una famiglia borghese, originaria di Diano Marina - il prénom francese indica che all'epoca il luogo di nascita del deputato nizzardo faceva parte dell' $85^{\circ}$ dipartimento delle Alpes-Maritimes della Repubblica transalpina -, iniziò giovanissimo la carriera giudiziaria, essendo stato nominato, il 9 novembre 1822, consigliere aggiunto presso la Corte di Nizza. Tuttavia abbandonò ben presto questo impiego per dedicarsi alla libera professione, che esercitò presso la Corte d'appello della città, I'ex Senato di Nizza, acquisendo la reputazione di abile giurista ${ }^{1}$.

Fin dal '48 iniziò a segnalarsi come uomo di tendenze liberali moderate incontrando il favore dei suoi concittadini, cosicché nel dicembre del 1849 si presentò alle elezioni per la IV legislatura del Parlamento subalpino, sostenuto sia dalla curia locale sia da cittadini progressisti ${ }^{2}$. Eletto il 10 dicembre di quell'anno nel primo collegio di Nizza, si trasferì a Torino e si inserì subito nel gruppo di deputati schierati con il conte di Cavour ${ }^{3}$, ottenendone la fiducia al punto che, pur essendo uomo nuovo nel mondo politico torinese, fu proposto dallo stesso Cavour

\footnotetext{
${ }^{1}$ Ratti, 1987, pp. 792-794; Riberi, 2019, pp. 229-260.

${ }^{2}$ Briano, 1857, pp. 13-14.

${ }^{3}$ Su Camillo Benso, conte di Cavour, cfr.: Cavour, I-XXI, 1962- 2012; De la Rive, 1862- 1863; Panzini, 1932; Cappa, 1932; Omodeo, I-II, 1940; Passerin d'Entrèves, 1956; Passerin d'Entrèves, 1979, pp. 120-138; Romeo, 1959; Id., I, 1969; Id., II, 1977; Id., III, 1984; Id., 1984; Guichonnet, 1961; Mack Smith, 1958; Id., 1958; Id., 1985; Id., 1999; Hearder, 1994; Cafagna, 1999; Viarengo (ed.), 2010; Viarengo, 2010; Talamo, 2010; Levra (ed.), 2011; Albano, 2017; Gentile (ed.), 2018.
} 
all'allora primo ministro d'Azeglio ${ }^{4}$ per la successione nel Governo al guardasigilli Filippo Galvagno, incarico che gli fu affidato il 7 luglio 1851 e che mantenne fino al 26 febbraio 1852.

In proposito è il caso di ricordare quanto, negli anni che vanno dal 1850 al 1852, la carica di ministro di Grazia e Giustizia e degli Affari Ecclesiastici fosse impegnativa e non scevra da imprevisti, dato il contenzioso di natura giurisdizionale apertosi con la Santa Sede, determinato dall'entrata in vigore delle "leggi Siccardi", che fu la principale causa dei frequenti avvicendamenti di ministri verificatisi in questo dicastero in quel periodo.

Nominato ministro, De Foresta seppe portare avanti, senza le rigidezze dottrinarie che avevano sovente impacciato l'azione di Siccardi, notevoli riforme dell'apparato giudiziario.

Ben introdotto nella buona società torinese, il neoministro fu un assiduo frequentatore del salotto della baronessa Olimpia Savio (che lo ricorda nelle sue Memorie), alla quale rimase sempre legato da un rapporto di cordiale amicizia ${ }^{5}$.

Su sua iniziativa la polizia giudiziaria passò alle dipendenze degli avvocati fiscali, e contemporaneamente venne prodotta una nuova normativa sull'istruzione dei procedimenti penali e sugli arresti (legge del 14 dic. 1851) che migliorava la tutela delle libertà personali. Tuttavia II mandato ministeriale di De Foresta, in questa prima fase della sua carriera politica, fu soprattutto legato alla legge del 26 febbraio 1852, che modificava in modo restrittivo lo Statuto albertino sulla libertà di stampa ${ }^{6}$. In effetti questa legge concedeva al pubblico ministero la facoltà di perseguire direttamente il reato di oltraggio nei confronti dei capi di Stato stranieri senza necessitare della relativa denuncia, pervenutagli attraverso il canale diplomatico. Ciò di fatto consentiva l'azione d'ufficio e costituiva una sorta di censura per i giornali. Paese e Parlamento non accolsero bene il provvedimento, che comunque riuscì a passare soprattutto per l'appoggio dei conservatori e dei clericali: il prezzo dell'operazione, richiesto dalla Sinistra rattazziana a D'Azeglio, fu però la testa del guardasigilli, che venne sostituito da Galvagno. Su pressioni di Cavour - che, dopo la sua uscita dal Governo per dissapori con D'Azeglio, stava avvicinandosi a Rattazzi, stipulando con quest'ultimo un'alleanza tra l'ala riformista della destra e la sinistra liberale e repubblicana che sarebbe stata poi definita con la metafora 'connubio' - De Foresta venne infatti sacrificato a causa dell'im-

\footnotetext{
${ }^{4}$ Su d'Azeglio cfr. Maturi, 1962, pp. 746-756; d'Azeglio, 1987-2016; Pichetto, Martellini, 2016. Sull'episodio - di rilevanza costituzionale - del Proclama di Moncalieri e sull'apporto di d’Azeglio, cfr. Pene Vidari, 2019, pp. 225-238; Id., 2020, pp. 332-345; Traverso, 2019a, pp. 161-178.

${ }^{5}$ Archivio di Stato di Torino, Sezioni Riunite, Archivio Savio, cartella n. 356, 25/30.

${ }^{6}$ Il progetto di legge Modificazioni alla legge sulla stampa del 26 marzo 1848, presentato da De Foresta alla Camera il 17 dicembre 1851, diventerà la Legge del 26 febbraio 1852, n¹337. Raccolta degli Atti del Governo di S. M. il Re di Sardegna, volume XX, Dal $1^{\circ}$ gennaio a tutto dicembre 1852, Torino, Stamperia reale, 1852, pp. 217-218.
} 
popolarità che gli derivava dall'avere legato il suo nome alla legge sulla stampa. Tuttavia anche il suo successore Galvagno, essendo avversato dal centro sinistra, fu costretto a lasciare, dei due ministeri che deteneva (Interni e Giustizia), quello degli Interni, di maggior prestigio politico, a Alessandro Pernati, già intendente generale di Torino e assai più vicino al gruppo cavouriano.

Rientrato nei banchi dei deputati dopo questa serie di vicissitudini, Giovanni de Foresta intervenne per difendere gli interessi del suo collegio elettorale (Nizza 1), quando - in nome dei princìpi liberali affermati nello Statuto albertino che aboliva i privilegi e i particolarismi locali in vigore durante l'Ancien Régime - fu necessario eliminare i porti franchi nel Regno di Sardegna e rivedere le tariffe doganali secondo i nuovi codici commerciali in vigore nello stato sabaudo.

II giurista nizzardo dedicò la sua ulteriore attività parlamentare all'elaborazione di un suo progetto di codice di procedura civile, che fu approvato e pubblicato nel '54. Questo lavoro fu giudicato da Carlo Dionisotti «molto imperfetto, infarcito di molte nullità e di prescrizioni inutili e dispendiose» ${ }^{7}$. Si trattò, peraltro, di un codice che fu in seguito rivisto e modificato più volte.

Nel 1855, sempre come deputato, De Foresta appoggiò la legge sulla soppressione di parecchie comunità religiose ${ }^{8}$ : in ogni caso, e con i suoi interventi in Parlamento, si rivelò nel complesso un abile e fedele sodale di Cavour, sostenendo la politica del primo ministro sintetizzata nella formula "Libera Chiesa in libero Stato".

Alla Camera la cosiddetta Legge sui conventi era stata approvata il 2 marzo 1855 , con 116 voti favorevoli e 36 contrari su 152 deputati presenti e votanti ${ }^{9}$. Tuttavia, in Senato, la legge incontrò una forte opposizione, che ebbe nel vescovo di Casale e senatore del Regno, Luigi Nazari di Calabiana ${ }^{10}$, il suo principale rappresentante. Questi, il 26 aprile 1855, fu autorizzato dalla Santa Sede ad offrire al Governo, a nome dell'episcopato piemontese, la somma necessaria al pagamento delle pensioni per i parroci, in cambio del ritiro della Legge. Egli non specificò le condizioni, in modo tale da consentire al Governo di operare una conciliazione.

II giorno dopo, constatato l'atteggiamento di Vittorio Emanuele II ${ }^{11}$, anch'egli contrario alla legge, e l'impossibilità di far passare al Senato il progetto originario,

\footnotetext{
${ }^{7}$ Dionisotti, 1881, p. 157.

${ }^{8}$ Legge del 19 maggio $1855 n^{\circ} 878$, con la quale vengono soppressi alcuni ordini religiosi, capitoli e benefizi, viene creata una Cassa ecclesiastica e fissata la quota annua di concorso da pagarsi dagli altri enti morali ecclesiastici. Raccolta degli Atti del Governo di Sua Maestà il Re di Sardegna, volume XXIV, anno 1855, Torino, Stamperia reale, 1855, pp. 741-752.

${ }^{9}$ Tornata del 2 marzo 1855 in Atti del Parlamento Subalpino - Discussioni della Camera dei Deputati, V Legislatura - Sessione 1853-1854 (19/12/1853 - 29/05/1855), Volume (VI) 3 A delle discussioni della camera dei deputati dal 28/11/1854 al 03/03/1855 Firenze, Tipografia Eredi Botta 1870, pp. 3115-3116.

${ }^{10}$ Cfr. Savio, 1939; Apeciti, 2013, pp. 63-66.

${ }^{11}$ Su Vittorio Emanuele II, cfr.: Mack Smith, 1972; Id., 1990, pp. 13-94; Cognasso (ed.), 1966; Gentile, 2011; Viarengo, 2017. Sulla costruzione del 'mito' del re galantuomo, cfr.
} 
Cavour rassegnò le dimissioni e con lui i ministri del suo primo gabinetto. Essendo tuttavia impossibile formare alla Camera una maggioranza alternativa, il Re fu costretto a confermare Cavour alla guida dell'esecutivo. Ma ciò rendeva necessarie le dimissioni da ministro di Grazia e Giustizia di Urbano Rattazzi ${ }^{12}$, latore della legge tanto contrastata, che le rassegnò il 27 aprile 1855, mantenendo peraltro il portafoglio degli Interni, conferitogli l'anno precedente. Perciò Cavour nominò guardasigilli il più moderato De Foresta, che sarebbe rimasto in carica per quattro anni, fino alla conclusione del suo secondo gabinetto, il 19 luglio 1859, ottenendo contemporaneamente la nomina a senatore (31/05/1855). Allineandosi alla politica di Cavour, che si era avvicinato alla sinistra anticlericale, De Foresta dovette inasprire il suo atteggiamento nei confronti della Chiesa. II 29 maggio 1855 il Nizzardo, nella veste di nuovo ministro della Giustizia e degli Affari Ecclesiastici, ratificò la legge Rattazzi - già approvata dalla Camera, e infine anche dal Senato il 10 maggio - che aboliva gli ordini religiosi privi di utilità sociale, ovvero che «non attendessero alla predicazione, all'educazione, o all'assistenza degli infermi», espropriandone tutti i conventi (334 case) e sfrattando 3733 uomini e 1756 donne. I beni di questi ordini soppressi furono conferiti alla Cassa ecclesiastica, persona giuridica distinta ed autonoma dallo Stato ${ }^{13}$.

Indubbiamente gli anni che vanno dal 1855 al 1859 costituirono il periodo più importante della carriera politica e dell'attività giuridica di De Foresta, durante il quale occorre segnalare due momenti chiave.

Il primo è nel febbraio 1858, quando De Foresta, per venire incontro alle richieste della Francia dopo l'attentato di Orsini contro Napoleone II $^{14}$, dovette presentare alla Camera una legge sulle sanzioni da infliggere ai cospiratori contro i capi di Stato stranieri, sull'apologia dell'assassinio politico per mezzo della stampa e sulla riforma delle giurie chiamate a giudicare i reati commessi a mezzo stampa, che fu approvata dal Parlamento subalpino il 20 giugno $1858^{15}$.

II secondo momento importante per De Foresta fu nel 1859, durante la seconda guerra di Indipendenza italiana e verso la fine del suo secondo mandato, quando

Levra, 1992, pp. 41-136 e Albano, 2017. Sulla formazione amministrativa e costituzionale di Vittorio Emanule II, cfr. Casana, 2020.

${ }^{12}$ Cfr. Pischedda, 2004; Balduzzi, Ghiringhelli, Malandrino (eds.), 2009; Rattazzi, 2013; Malandrino, 2014; Id., 2016, pp. 558-562

${ }^{13}$ Sulla crisi politica provocata dall'opposizione alla legge «sui conventi», cfr. Romeo, III, 1984, pp. 121-134.

${ }^{14}$ Cfr. Procès de Orsini, de Rudio, Gomez, Pierri et Bernard: attentat du 14 janvier 1858 contre la vie de S.M. Napoléon III, Empereur des français, Brienne, G. Martin, 1858, e Dansette, 1964.

${ }^{15}$ Si tratta della legge 20 giugno $1858 n^{\circ} 2876$ concernente la cospirazione contro la vita dei Sovrani stranieri, l'apologia dell'assassinio politico, e la riforma della nomina del giurì, in Raccolta degli Atti del Governo di S. M. il Re di Sardegna, volume XXVII, Anno 1858, Torino, Stamperia reale, s.d., pp. 217-220. 
Cavour rifiutò di controfirmare il decreto reale che conferiva a Rosa Vercellana ${ }^{16}$ il titolo di Contessa di Mirafiori, perché temeva che ciò offrisse a Vittorio Emanuele II, vedovo di Maria Adelaide d'Asburgo dal 1855, la possibilità di un matrimonio con la sua amante, compromettendo quella di nuove nozze del re con una principessa di sangue reale. Ne scaturì un dissenso tra il Presidente del Consiglio e il suo ministro degli Interni Rattazzi, che era favorevole alla concessione del titolo nobiliare alla Vercellana in modo da permettere a Vittorio Emanuele II sia un'unione sia religiosa sia civile con 'la bella Rosina', come in effetti avvenne una decina d'anni dopo. A risolvere la questione intervenne De Foresta, che in veste di ministro della Giustizia, sdrammatizzò la situazione, sottoscrivendo il decreto di nobilitazione della Vercellana.

Ma a causa delle dimissioni di Cavour, in seguito all'Armistizio di Villafranca, a cui subentrò dal 19 luglio 1859 al 21 gennaio 1860 il governo La Marmora, De Foresta dovette cedere il dicastero a Miglietti, designato da La Marmora come nuovo ministro della Giustizia.

Alla presidenza del Consiglio di La Marmora succedettero due governi Cavour. Al dicastero della giustizia di entrambi i suoi ultimi gabinetti, il Conte non chiamò più De Foresta. Ciò non tanto per sfiducia nell'uomo, che aveva dato buona prova di sé, quanto per il fatto che probabilmente non riteneva opportuno inserire un nizzardo nelle due ultime sue compagini governative: nel penultimo gabinetto perché il Conte, appressandosi a cedere Nizza per onorare gli accordi di Plombières ${ }^{17}$, pensava fosse provocatorio nei confronti della Francia mantenere De Foresta nel suo governo date le sue origini francofone; nell'ultimo suo gabinetto perché occorreva dare al suo primo ministero, non più subalpino, ma nazionale, un carattere il più italiano possibile attraverso un amalgama di rappresentanti di tutte le regioni del Paese, quando il territorio, in cui l'ex ministro della Giustizia era stato eletto negli anni Cinquanta, ormai non faceva più parte dell'Italia.

Forse anche per queste ragioni, nel mese di giugno del 1860, De Foresta, dopo aver tenuto in Senato un discorso in cui esprimeva tutta la sua delusione e il

\footnotetext{
${ }^{16}$ A proposito della "bella Rosina" cfr.: Borelli, 1989, p. 235; Romeo, 1984, pp. 394-395; Viarengo, 2010, pp. 372-373; Oliva, 1998, pp. 396-400.

17 Sull'annessione di Nizza alla Francia: Carteggio Cavour-Nigra, 1929; Latouche, 1954; Compan, 1973; Gonnet, 2003; Barelli - Rocca, 1995; Guichonnet, 2003, pp. 317-329; Genta, 2001, pp. 34-43; Casana, 2001, pp. 11-31; Ead., 2010, pp. 81-104; Ruggiero (ed.), 2006; Vernier, 2009, pp. 345-349; Sorrel, 2010, pp. 8-15; Schor-Courrière (eds.), 2011; Ortolani-Bruno Berthier (eds.), 2013; Milbach (ed.), 2010; Tombaccini, 2009, pp. 91-99; Gandolfo, 2011, pp. 107-160. La presente bibliografia è da integrarsi con i saggi del volume sui Plebisciti, curato da Gian Savino Pene Vidari nel 2016: Montaldo, pp. 13-21; Soffietti, pp. 23-49; Casana, pp. 51-71; Ead., pp. 239-250; Cernigliaro, pp. 71- 88; Genta, pp. 89- 107; Pene Vidari, pp. 109-123; Roccia, pp. 123-140; Ortolani, pp. 187-216; Berthier, pp. 217-221. Sull'importanza dei plebisciti per la formazione del Regno d'Italia, cfr. Mongiano, 2003.
} 
dispiacere per la cessione di Nizza alla Francia ${ }^{18}$, optò per la nazionalità italiana, ottenendo il titolo di conte e la nomina a primo presidente della Corte d'Appello di Bologna.

Gli ultimi anni della carriera di De Foresta vedono il giurista impegnato sia sul piano della sua professione di magistrato sia su quello di membro del parlamento italiano: come senatore del Regno nel 1863 partecipò alla Commissione del Senato per l'esame del progetto Pisanelli relativo al codice civile, mentre come membro della Commissione parlamentare penale si oppose all'abolizione della pena di morte, già approvata alla Camera. Tra il 1865 e il 1872, la sua attività parlamentare si ridusse gradualmente: in ogni occasione, De Foresta si dimostrò tuttavia tenace sostenitore di una moderata autonomia della magistratura rispetto alla politica, sostenendo al contempo la riorganizzazione della Cassazione intesa come «Corte di revisione decentrata» ${ }^{19}$.

Decorato nel 1862 della Gran Croce dell'Ordine Mauriziano, nel '68 ebbe le insegne di grand'ufficiale dell'Ordine della Corona. Morì a Bologna il 14 febbraio 1872.

\section{Gli interventi di De Foresta alla Camera subalpina}

De Foresta sedette alla Camera subalpina per due legislature, la IV e la V, e rivesti due importanti incarichi di governo: ministro di Grazia e Giustizia e degli Affari del Culto (dal 07.07.1851 al 26.02.1852) nel primo governo D'Azeglio e ministro di Grazia e Giustizia e degli Affari Ecclesiastici (dal 04.05.1855 al 19.07.1859) nel secondo governo Cavour.

Nel corso della sua attività parlamentare presentò 28 progetti di legge ed effettuò altri numerosi interventi.

In questo articolo sarà presentato innanzitutto il progetto discusso durante il periodo del suo primo incarico ministeriale, vale a dire quello che si tradusse nella legge del 26 febbraio 1852 sull'introduzione di misure restrittive della libertà di stampa garantita dallo Statuto, consistenti nella modifica dell'art. 25 e nell'abrogazione dell'art. 54 dell'Editto del 26 marzo 1848 relativamente ai crimini di offesa ai capi di Stato stranieri ${ }^{20}$.

\footnotetext{
${ }^{18}$ Atti del Parlamento Italiano, Sessione del 1860 (VII Legislatura), dal 2 aprile al 28 dicembre 1860, volume IV Unico delle discussioni del Senato del Regno, Roma, Eredi Botta, 1878 , p. 100.

${ }^{19}$ D'Addio, 1966, pp. 122-126.

${ }^{20}$ Legge Modificazione all'art. 25, ed abrogazione dell'art. 54 dell'editto del 26 marzo 1848 sulla libertà della stampa, Atto n¹337, in Raccolta degli Atti del Governo di S. M. il Re di Sardegna, vol. XX, dal $1^{\circ}$ gennaio a tutto dicembre 1852, s.d., pp. 217-218. L'editto del 26 marzo 1848, all'art. 25, prevedeva che "le offese contro i Sovrani o i Capi dei Governi stranieri saranno punite col carcere estensibile a sei mesi e con multa da lire 100 a 1000». Atto n695, in Raccolta degli Atti del Governo di S. M. il Re di Sardegna, vol. XVI, Dal $1^{\circ}$ gennaio a tutto dicembre 1848, s.d. pp. 233-261.
} 
Sarà successivamente riservata la dovuta attenzione ai dibattiti parlamentari in cui furono discussi i progetti portati avanti dal 1854 al 1859, la maggior parte dei quali durante il secondo governo Cavour: questi ultimi rivestono una certa importanza per l'evoluzione del lavoro legislativo nella redazione dei codici sabaudi, iniziato nel 1831 per volontà di Carlo Alberto. Sono questi gli anni più intensi dell'attività giuridica di De Foresta perché le sue proposte affrontano direttamente la riforma dei codici, e in particolare del codice di procedura civile e del codice penale.

Nel 1854 è la volta del progetto di codice di procedura civile, che viene approvato in via provvisoria, a cui seguirà un progetto di revisione per l'approvazione definitiva del medesimo, presentato alla Camera il 24 giugno 1858.

De Foresta, tra 1856 e '57, promosse anche altri disegni di legge indirizzati a riformare l'ordine giudiziario, o meglio il funzionamento delle corti e dei tribunali. Nel 1856, nella tornata del 26 marzo, ripresentò un progetto di legge riguardante la riorganizzazione dell'ordine giudiziario e del Ministero pubblico, proponendo che fosse rinviato all'esame della Commissione che già ne era stata incaricata nella sessione del $1853^{21}$, ed inoltre altri tre progetti: I'uno per l'istituzione nella Corte di cassazione di una Commissione incaricata del primo esame dei ricorsi; l'altro per la creazione di una classe temporanea nella Corte di appello di Torino, e di una sezione anch'essa temporanea in ciascuno dei tribunali provinciali di Torino, Genova e Vercelli; il terzo contemplante provvedimenti riguardanti le segreterie delle Corti, dei tribunali e delle giudicature.

Nel '57 si occupò del codice penale attraverso una proposta intitolata Modificazioni al Codice penale, annunciata alla Camera il 9 gennaio insieme ad altre tre, riguardanti l'organizzazione dell'ordine degli avvocati, l'abolizione della tassa sugli interessi convenzionali, l'istituzione di due tribunali di commercio nell'isola di Sardegna, uno a Cagliari e l’altro a Sassari.

Ritenendolo, poi, degno di particolare attenzione, ho esaminato più da vicino il contributo dato da De Foresta alla politica di Cavour ed a questo scopo sono stati scelti i suoi interventi parlamentari come deputato in appoggio al progetto di legge intitolato Soppressione di comunità e stabilimenti religiosi ed altri provvedimenti per migliorare la condizione dei parrochi più bisognosi, presentato da Rattazzi e da Cavour nel novembre del 1854, che per diventare legge ebbe bisogno di un lungo iter parlamentare e causò le dimissioni del primo governo Cavour.

Per la medesima ragione sono state considerate le argomentazioni di De Foresta in difesa del progetto relativo alla cospirazione contro i capi di Stato esteri, sull'apologia dell'assassinio politico a mezzo della stampa e sulla riforma delle giurie, da lui stesso presentato alla Camera il 17 febbraio 1858. L'attentato di

\footnotetext{
${ }^{21}$ Un primo progetto era stato presentato il 7 dicembre 1850 dal deputato Pescatore; un secondo progetto - articolato in due parti, Riordinamento dell'ordine giudiziario e del pubblico ministero. Istituzione delle Assise coi giurati - fu presentato da Rattazzi nella sessione 1853-1854, il 27 dicembre '53 e il 17 maggio 1854.
} 
Felice Orsini, avvenuto un mese prima (il 14 gennaio), metteva a rischio l'intesa con la Francia allontanando un possibile alleato del Regno Sardo: Napoleone III aveva infatti reagito sia facendo approvare leggi severe che limitavano la libertà personale e di stampa, sia richiedendo agli altri Stati, e specialmente al Piemonte, di porre restrizioni alle attività degli esuli. Il governo piemontese e il suo primo ministro Cavour si trovarono dunque nella necessità di dare una qualche risposta a tale richiesta, che accolsero parzialmente con la legge del 20 giugno 1858. Essa limitava la libertà di stampa unicamente in relazione all'apologia dei reati politici, introducendo all'art. 2 il reato di «apologia dell'assassinio politico per mezzo della stampa». Grazie a De Foresta che, nel corso del dibattito, contrastò attraverso solide argomentazioni giuridiche le decise contestazioni dell'opposizione, appoggiando fattivamente la politica di Cavour, il progetto fu approvato il 29 aprile, benché con un discreto numero di voti contrari (42) contro i 110 favorevoli.

\section{L'approvazione della nuova legge sulla stampa del 26 febbraio 1852 e le sue conseguenze politiche}

Gli anni 1851-'52, nella vita politica del Regno di Sardegna, paiono privi di grandi avvenimenti politici e militari: costituiscono piuttosto un periodo di revisione delle idee, di riposizionamento ideologico dei partiti, di posizioni ideologiche, di crisi che non si esauriscono, ma si risolvono in rinnovamento delle forze in campo ${ }^{22}$.

Risalgono a questi anni la stipula di nuovi trattati di commercio, che vengono uniformati ai principi del libero scambio allo scopo di procurare all'industria materie prime a buon prezzo, la promulgazione di nuove leggi societarie e la creazione di nuove istituzioni bancarie, nonché la promozione delle costruzioni ferroviarie e navali. Tutto ciò costituisce una risposta all'ascesa della borghesia, che l'attività legislativa e l'azione di governo di Cavour, ministro dell'economia e delle finanze, intendevano sostenere, appoggiandosi alle classi sociali emergenti.

Inoltre, poiché in gran parte degli altri Stati della Penisola una vita politica democratica era impossibile per l'interferenza dell'impero austriaco, ancora legato ai principi della Restaurazione, i patrioti italiani ripararono in Piemonte, anche se molti di questi fuoriusciti non erano particolarmente graditi al governo sabaudo. Nonostante ciò, gli emigranti provenienti dai diversi territori italiani si conobbero, impararono a vivere insieme e si inserirono agevolmente nella vita politica del regno di Sardegna, mettendo da parte alcuni dei molti loro pregiudizi municipalistici e convertendosi finalmente all'idea unitaria. È significativo, sotto questo aspetto, che la maggior parte dei direttori e dei collaboratori dei giornali di Torino fossero degli immigrati.

Alla fine del 1851 il colpo di Stato di Luigi Napoleone aveva allarmato sia i democratici sia i liberali, rendendo più acceso il dibattito parlamentare e dando

\footnotetext{
${ }^{22}$ Sul momento storico-politico e sulle vicissitudini per l'approvazione della legge leggasi Rodolico, III, 1966, pp. IX-XXIII.
} 
speranze ai più rigidi conservatori di una sterzata a destra del governo. Qualche tempo dopo i gabinetti di Vienna e di Berlino avevano consigliato a quello di Torino di seguire l'esempio degli altri Stati italiani, in cui la libertà di stampa veniva sistematicamente coartata. Durante la primavera del 1852 D’Azeglio rispondeva, a nome del Re, che non intendeva ascoltare questi suggerimenti ${ }^{23}$. Tuttavia il colpo di Stato di Luigi Napoleone aveva dato occasione ai patrioti italiani immigrati in Piemonte di scagliarsi a mezzo stampa contro l'autoritarismo napoleonico con frasi oltraggiose e vignette di dubbio gusto, tanto che sia D'Azeglio sia Cavour ritenevano che rendersi ostili a Luigi Napoleone con questo tipo di provocazione era un errore assolutamente da evitare.

La posizione di Cavour divenne assai delicata: egli non poteva opporsi al provvedimento, perché avrebbe dovuto dimettersi dal governo e lasciare mano libera alla Destra, cioè compiere un atto di aperta ostilità verso D'Azeglio, il re e il governo francese che l'aveva richiesto; il Conte d'altra parte non voleva neppure confondere la sua posizione con quella dei conservatori, perché ciò avrebbe significato un'aperta rinuncia alla politica da lui tenacemente perseguita negli ultimi due anni. Decise pertanto di sostenere il progetto di legge sulla stampa proposto dal ministro della Giustizia De Foresta, ma di far sì che la sua posizione si differenziasse da quella dei più moderati azegliani. A tale scopo strinse un accordo esplicito con Rattazzi, che il suo fidato amico Castelli aveva già preparato nei mesi precedenti24.

La nuova legge sulla stampa prevedeva che nei processi per offese ai Capi di Stato il giudizio venisse sottratto alle giurie popolari, come stabiliva lo Statuto albertino ${ }^{25}$, e fosse deferito ai Tribunali ordinari al fine di procedere con la maggiore celerità possibile in caso di infrazione delle norme previste dal codice penale.

Iniziato il 3 febbraio 1852, il dibattito sul disegno legge si protrasse fino al 10 febbraio 1852.

La discussione generale della legge cominciò alla Camera il 3 febbraio con la lettura dell'articolo unico costituente il progetto del Ministero e della controproposta elaborata dalla Commissione della Camera, che ad esso sostituiva una serie di disposizioni sintetizzate in cinque articoli nei quali si dichiarava 'ammissibile' che l'azione penale fosse esercitata in seguito alla richiesta diplomatica subordinandola però all'attestazione da parte del ministro degli esteri (art. 1) e si manteneva la competenza della giuria, pur riformandone le modalità di composizione

\footnotetext{
${ }^{23}$ Romeo, II, 1977, p. 558.

${ }^{24}$ Castelli, 1886, p. 41.

${ }^{25}$ L'istituto della diretta partecipazione del popolo all'amministrazione della giustizia venne introdotto nel regno di Sardegna con il R.D. 26 marzo 1848 n. 695 editto sulla stampa il cui articolo 78 prevedeva che i reati commessi con tale mezzo di diffusione del pensiero fossero giudicati dalla Corte d'appello assistita per il giudizio del fatto da dodici giurati tratti a sorte dalle liste degli elettori politici. Scaparone, 2012, p. 61.
} 
(artt. 2-5) ${ }^{26}$.

Al progetto ministeriale subito furono opposte due questioni pregiudiziali, la prima da parte del giurista Matteo Pescatore e la seconda da Sebastiano Tecchio, entrambi esponenti della sinistra.

Pescatore, pur non contestando la necessità «di provvedere che la stampa sia contenuta in limiti tali nelle sue discussioni sulla politica estera, che siano salve a un tempo, e la giustizia, e la convenienza politica, e la indipendenza del nostro paese», esprimeva il suo dissenso per i mezzi che si intendevano adottare: attribuire «la cognizione delle offese verso i capi dei Governi stranieri ai magistrati ordinari, togliendo la competenza del giurì» gli pareva poco conforme ai principi delle libere istituzioni del Regno ${ }^{27}$.

Tecchio poneva, invece, la questione pregiudiziale circa l'irritualità di una legge, che avrebbe dovuto essere promulgata non tanto nell'interesse della nazione quanto su sollecitazione di potenze straniere:

[...] il tema stesso della legge, e i motivi addotti dal signor ministro, e le manifestazioni fatteci dai commissari, mi dimostrano che la legge è l'effetto di influenze straniere, colle quali non parmi che possa bene coesistere l'autonomia nazionale, per questo appunto io desidero che la legge sia tolta di mezzo con decreto preliminare; tolta di mezzo, senza guardare addentro alle sue disposizioni, e senza tampoco riflettere se desse alla libera stampa scemino le guarentigie ${ }^{28}$.

Ai due interventi seguì quello di D'Azeglio, presidente del Consiglio e ministro degli Affari esteri, che, dopo avere dichiarato che la legge in discussione non era il portato di alcuna «influenza straniera», bensì "dell'idea di giustizia, dell'idea di onore e di buon senso» che la rendevano necessaria, affrontò la questione dal punto di vista del carattere 'pubblico' ormai assunto da gran parte dei fenomeni della società del suo tempo: le comunicazioni più facili, le accresciute possibilità di contatti e scambi di idee fra le persone, e soprattutto la libertà di stampa. Quest'ultima era, a suo avviso, un bene da tutelare, come tutte le altre forme di libertà, ma difficile da gestire e destinata a venire meno quando non fosse esercitata secondo il criterio che qualifica qualsiasi forma di libertà, cioè nel pieno rispetto della libertà altrui. Per questa ragione:

La libertà della stampa, come tutte le altre, debbe esprimere giustizia. Se essa ciò non significasse, se essa non si facesse tutela del diritto comune, di tutti i diritti, del diritto sociale, del diritto politico, del diritto civile, del diritto religioso, di tutti i diritti che tanto sono cari agli uomini, le succederebbe quello che è avvenuto a

\footnotetext{
${ }^{26}$ Tornata del 3 febbraio 1852, in Atti del Parlamento Subalpino, Discussioni, (VIII) 6 A, 1866, pp. 4054.

${ }^{27}$ Intervento di Matteo Pescatore, Tornata del 3 febbraio 1852, in Atti del Parlamento Subalpino, Discussioni, (VIII) 6 A, 1866, p. 4054.

${ }^{28}$ Intervento di Sebastiano Tecchio, Tornata del 3 febbraio 1852, in Atti del Parlamento Subalpino, Discussioni, (VIII) 6 A, 1866, p. 4058.
} 
molte altre libertà. A poco a poco gli uomini direbbero: questa non è libertà, questa è prepotenza di pochi, questa è setta, questo è compagnonaggio. La libertà della stampa verrebbe a noia, tornerebbe in dispregio, scadrebbe nell'opinione; e quando una istituzione non è più accetta all'opinione pubblica, siate certi, poco starà ch'essa perisca ${ }^{29}$.

Dopo gli interventi di alcuni membri della Commissione della Camera ${ }^{30}-\mathrm{Pi}$ nelli, Lanza, Daziani e del relatore Miglietti, il quale chiarì che all'interno della Commissione non c'era mai stata unanimità sul progetto complessivo, a causa dei profondi contrasti sui principi ispiratori della legge, come risultava anche dalla relazione ${ }^{31}$-, la questione pregiudiziale posta da Tecchio fu rigettata, mentre Pescatore chiese che la sua fosse messa ai voti al termine della discussione generale.

Nella sua relazione la Commissione, oltre a ricordare che il progetto aveva generato inquietudini nell'opinione pubblica, si dichiarava meravigliata nel rilevare che, volendo modificare la legislazione sulla stampa, il progetto ministeriale si limitasse ad una "correzione restrittiva». Quest'ultima riguardava una parte della legge del 1848 dalla quale non era derivata «alcuna funesta conseguenza originata dal sistema di libertà »: ciò induceva a pensare che il Ministero subisse pressioni, lesive dell'autonomia della nazione, da parte di potenze straniere e, di conseguenza, a considerare la presentazione del progetto come «indizio e iniziamento di un sistema retrivo» e a tal punto inopportuna che la Commissione, contraria alla sua adozione, chiedeva chiarimenti in merito al Ministero ${ }^{32}$. Le giustificazioni addotte dal Governo negavano l'esistenza di influenze specifiche, pur riconoscendo che alla proposta della legge si era stati indotti «e dalla necessità dei tempi, e da autorevoli consigli». Si affermava comunque che una misura più repressiva era «una ineluttabile necessità » a causa del «contegno spesso indecente di una parte della stampa quotidiana ${ }^{33}$.

Nella seduta del 4 febbraio con un lungo intervento il ministro De Foresta si propose di giustificare i contenuti del progetto alla luce dalle critiche mossegli dalla Commissione designata dal Parlamento per l'esame del progetto di legge.

De Foresta ragionò sui due obiettivi contenuti nei due paragrafi della proposta di legge: facilitare l'esercizio dell'azione penale nei confronti dei reati di offesa ai

\footnotetext{
${ }^{29}$ Intervento di Massimo d'Azeglio, Tornata del 3 febbraio 1852, in Atti del Parlamento Subalpino, Discussioni, (VIII) 6 A, 1866, p. 4061.

${ }^{30}$ Dagli "uffizi camerali" erano stati designati come membri della Commissione per l'esame del progetto di legge i deputati Castelli, Moffa di Lisio e Pinelli, della maggioranza governativa; Lanza, Sineo, Daziani e Miglietti, della sinistra; a Miglietti fu affidato il compito di riferire alla Camera, presieduta dall'onorevole Pier Dionigi Pinelli.

31 Intervento di Vincenzo Miglietti, in Atti del Parlamento Subalpino, Discussioni, (VIII) 6 A, 1866, p. 4064.

${ }^{32}$ Relazione presentata alla Camera il 24 gennaio 1852 dalla Commissione, in Atti del Parlamento Subalpino, Documenti, II, 1865, pp. 1179-1180.

${ }^{33}$ Atti del Parlamento Subalpino, Documenti, II, 1865, p. 1180.
} 
sovrani e ai capi di Governi stranieri, al quale tendeva il primo, e assicurare più efficacemente la punizione dei colpevoli, a cui doveva provvedere il secondo.

Spiegò che, per raggiungere il primo scopo, si era scelta la soluzione di facilitare il più possibile la richiesta della parte offesa al pubblico ministero di procedere senza prescrivere «né come, né in qual forma questa richiesta debba pervenirgli». In quanto, poi, alla proposta di lasciare la competenza del giudizio di tali reati ai tribunali ordinari, il ministro tenne a precisare che né il Ministero né lui personalmente erano contrari all'istituzione della giuria. In proposito formulò un giudizio positivo affermando:

Il Ministero in massima generale non è per certo avverso all'istituzione dei giurati, ed io nel mio particolare non temo di dichiarare e come ministro e come deputato, che sono profondamente convinto che l'istituzione dei giurati applicata anche ai reati comuni è eminentemente utile all'amministrazione della giustizia, giovevole alle finanze pel minore spiazzamento dei rei e dei testimoni, e, ciò che più monta, è quella fra tutte le liberali istituzioni che maggiormente giovi a moralizzare le popolazioni, ad eccitare la dignità di cittadino, l'amore ed il rispetto alle leggi ed alla giustizia ${ }^{34}$.

De Foresta, tuttavia, essendo tale questione così seria da non poter essere decisa in tempi brevi, riteneva "pericoloso» e "imprudente il fare alcune parziali modificazioni all'attuale organizzazione dei giudici del fatto, alla vigilia d'una discussione solenne, nella quale si tratterà di vedere se sia il caso di applicarla anche ai reati comuni, e pertanto di una organizzazione più ampia e generale» ${ }^{35}$.

Non giudicando opportuno indicare chi altro dovesse essere incaricato di scegliere i giurati, si limitò a ribadire che anche questa era una questione importante, da affrontare tenendo conto sia delle esigenze dell'amministrazione della giustizia sia delle garanzie per i cittadini, e perciò nel quadro di un riordinamento giudiziario complessivo. In effetti, tra il 1856 e il 1857 ormai senatore e nuovamente ministro di Grazia e Giustizia, De Foresta presentò un progetto di legge concernente la riorganizzazione dell'ordine giudiziario e del pubblico ministero, proponendo di affidarne l'esame alla stessa Commissione che aveva già avuto l'incarico di esaminare quello del 1852.

In quanto all'art. 5, l'attribuzione al giudizio dei giurati anche dei reati contro la religione era, secondo De Foresta, inopportuna in quel particolare momento; inoltre, poiché l'art. 14 della legge del '48 faceva riferimento agli artt. 164 e 165 del Codice penale che punivano gli attacchi contro la religione «con principi alla medesima contrari» ${ }^{36}$, il giurista, riferendosi ad un processo svoltosi a Nizza contro un giornale che aveva pubblicato "gli scritti di uno straniero, che pretende-

\footnotetext{
${ }^{34}$ Intervento di Giovanni de Foresta, Tornata del 4 febbraio 1852, in Atti del Parlamento Subalpino, Discussioni, (VIII) 6 A, 1866, p. 4067.

${ }^{35}$ Atti del Parlamento Subalpino, Discussioni, (VIII) 6 A, 1866, p. 4067.

${ }^{36}$ Cfr. Codice penale per gli Stati di S.M. il Re di Sardegna, 1839.
} 
va dimostrare che le pene dell'inferno non fossero perpetue», si chiedeva quale credibilità potrebbero avere le sentenze di una giuria su questioni di carattere teologico ${ }^{37}$.

In seguito autorevoli deputati della Destra conservatrice come Balbo, Revel e Menabrea sostennero che sarebbe stato opportuno dare maggiore sviluppo alla proposta di legge, fissando nuove restrizioni in materia di stampa.

I deputati della Sinistra combatterono vivacemente tale proposta, e particolarmente Rattazzi, in nome della libertà di stampa. Nonostante il dibattito si fosse protratto per diversi giorni, il presidente del Consiglio D’Azeglio - sia per motivi di salute sia perché temeva che la discussione degenerasse - partecipò soltanto alle sedute di apertura e di chiusura, limitandosi ad interventi piuttosto laconici, senza entrare nel merito delle singole proposte. In sua vece intervenne Cavour, in veste di ministro delle Finanze, del Commercio e dell'Agricoltura, affermando che condivideva molte delle idee di Rattazzi, perché egli stesso riteneva che ulteriori restrizioni in materia di stampa potessero costituire una minaccia per la libertà e che prendeva atto della promessa di Rattazzi «di accordare al ministero nella ventura sessione, in vista delle gravi circostanze in cui versava il paese, il suo appoggio». Non si dovevano nutrire timori per la libertà della stampa all'interno dello Stato, perchè essa non poteva "produrre gravi inconvenienti, od avere conseguenze tali da richiedere provvedimenti energici e straordinari di repressione ${ }^{38}$.

Era evidente l'allusione ad un intervento di Menabrea del giorno precedente, ma Cavour la volle rendere esplicita con l'intenzione di dissociarsi completamente dalla posizione conservatrice del deputato savoiardo ed arrivare ad una rottura, sostenendo:

Queste mie dichiarazioni basteranno, spero, a far convinta la Camera che io non posso nè punto nè poco sottoscrivere all'opinione manifestata nella tornata di ieri dall'onorevole deputato Menabrea, non potendo il Ministero in verun modo ammettere che sia necessario di mutare radicalmente la legge sulla stampa nello scopo di rendere la repressione di questa molto più efficace. II Ministero non ha questa convinzione; i membri che lo compongono dichiarano anzi che ove una tale proposizione fosse fatta nel seno di questa Camera, e partisse o dai banchi dei deputati, od, in altre circostanze, dai banchi del Ministero, essi la combatterebbero risolutamente. Forse questa mia dichiarazione sarà tacciata d'imprudenza, poichè, dopo di essa, il ministero deve aspettarsi di perdere in modo assoluto il debole appoggio che da qualche tempo esso riceveva dall'onorevole deputato Menabrea e da' suoi amici politici. Ma il Ministero lo ha dichiarato nell'esordire in questa discussione, nelle attuali gravissime circostanze crede essere primo dovere d'ogni uomo politico di manifestare chiaramente e schiettamente le proprie intenzioni, di spiegare al cospetto del Parlamento e della nazione quale è lo scopo che si pro-

${ }^{37}$ Intervento di Giovanni de Foresta, Tornata del 4 febbraio 1852, in Atti del Parlamento Subalpino, Discussioni, (VIII) 6 A, 1866, p. 4070.

${ }^{38}$ Intervento di Camillo Benso, conte di Cavour, Tornata del 5 febbraio 1852, in Atti del Parlamento Subalpino, Discussioni, (VIII) 6 A, 1866, pp. 4090-4092. 
pone di raggiungere, quale è la condotta che intende tenere. Quindi, desiderando che non vi possano essere illusioni a questo riguardo, io mi stimai obbligato a fare cotale dichiarazione, quantunque, lo ripeto, essa debba condannare il Ministero alla perdita di un alleato potente per la parola, e debba costringere me forse a ricominciare le ostilità coll'onorevole deputato Menabrea ${ }^{39}$.

Quando Cavour, dopo aver posto la questione di fiducia sulla legge, finì di parlare, tra "vivi segni d'approvazione e conversazioni su tutti i banchi» ${ }^{40}$, Menabrea raccolse la sfida lanciatagli, e rispose brevemente, ma in modo da puntualizzare l'evoluzione della situazione politica, oramai nettamente delineata: il suo era ormai un "debole appoggio» al Governo dal momento che il ministro delle Finanze intendeva «approdare ad altri lidi parlamentari»:

Maintenant, M. le ministre avec une convenance parfaite a parlé du faible appui que j'apporte aù Ministère. C'est vrai, $M$. le ministre a raison : en effet il doit se souvenir que plus d'une fois je me suis trouvé dans des rangs opposés aux siens et je m'en fais honneur. Monsieur le ministre, si veut faire voile vers d'autres rives parlementaires, aborder à d'autres rivages, il en est bien maître, mais je ne l'y suivrais pas; quant à moi, quelques soient les hommes qui siègeront sur les bancs du pouvoir, ils me trouveront toujours fidèle au même poste; j'ai pour principe de ma conduite, de ne jamais céder ni à l'amour de la popularité, ni aux considérations personnelles, ni aux tactiques politiques; mais je ne prends pour règle de ma vie que les profondes convictions qui m'animent, convictions que, je l'espère, ne m'abandonneront jamais ${ }^{41}$.

Al di là della normale dialettica parlamentare, la parte più significativa di questo dibattito consiste proprio nel confronto tra Cavour e Menabrea: a scontrarsi sono due visioni politiche antitetiche.

Menabrea concepisce il futuro del Regno di Sardegna come un'aggregazione di "petites patries" in un contesto transnazionale e dinastico, di cui casa Savoia, vera e propria sentinella dei territori al di là e al di qua delle Alpi occidentali, tutela le tradizioni, in primis quelle religiose e linguistiche - l'idioma francese che Menabrea usa nel suo discorso alla Camera, peraltro consentito dallo Statuto, è nel contempo esemplare e strumentale -.

Cavour, invece, persegue il fine di fondare una nuova nazione che parta dal Piemonte per aggregare ad esso gli stati italiani, uscendo dal provincialismo sabaudo e facendo del liberalismo, inteso in senso economico ed istituzionale, il principio della sua azione politica.

Durante il vivace dialogo intercorso tra i due (definito da Giovanni Lanza "inci-

\footnotetext{
${ }^{39}$ Atti del Parlamento Subalpino, Discussioni, (VIII) 6 A, 1866, p. 4092.

${ }^{40}$ Atti del Parlamento Subalpino, Discussioni, (VIII) 6 A, 1866, p. 4096.

${ }^{41}$ Intervento di Louis Frédéric Menabrea, Tornata del 5 febbraio 1852, in Atti del Parlamento Subalpino, Discussioni, (VIII) 6 A, 1866, p.4097.
} 
dente" ${ }^{42}$ ), occorre osservare come il conte di Cavour con grande abilità retorica - intuendo che Menabrea si sarebbe fatto interprete dei pensieri della destra più conservatrice in materia di libertà della stampa, e che così gli avrebbe fornito l'opportunità di rifiutare in nome del Ministero l'appoggio di Menabrea stesso e del gruppo dei deputati più integralisti, per accettare, in cambio, l'appoggio offerto da Rattazzi - eviti di rispondere immediatamente al discorso di Rattazzi, attaccando direttamente Menabrea e provocandolo in modo da ottenere la risposta che attendeva, per ritornare infine a dialogare con Rattazzi.

Fu a questo punto della discussione che Thaon de Revel, rivolgendosi a Cavour, affermò, usando un linguaggio metaforico piuttosto ironico, di essersi stupito per aver assistito - contemporaneamente al divorzio del ministro delle Finanze dalla maggioranza di destra - al matrimonio ('connubio') con l'opposizione di sinistra ${ }^{43}$. Cioè, fuor di metafora, che Cavour intendeva far cadere il governo in carica, dopo averlo messo in minoranza e trasformarlo da governo di centro-destra in uno di centro-sinistra, come di fatto avvenne qualche mese dopo, con la formazione del primo ministero Cavour (4 novembre 1852- 4 maggio 1855).

Giungeva così a maturazione un'importante svolta politica, il cui peso nello sviluppo della vita democratica e nella crescita economica del Piemonte è indubbio: in questo senso va vista l'alleanza tra la destra e la sinistra liberale che consentì a Cavour di conciliare gli interessi delle frange più avvertite della borghesia e dell'aristocrazia, superando l'immobilismo di D'Azeglio e realizzando le riforme politiche ed economiche necessarie nell'arco temporale della storia italiana denominato 'decennio di preparazione'.

Il dibattito sul progetto, intitolato Modificazioni alla legge sulla stampa del 26 marzo 1848, si concluse quindi con l'approvazione della proposta del Governo con 98 voti favorevoli e 42 contrari; al Senato il progetto fu discusso nelle tornate del 23 e 24 febbraio ed approvato con 49 voti favorevoli e 3 contrari. In tal modo entrò in vigore la legge del 26 febbraio $1852^{44}$, che modificava in modo restrittivo lo Statuto albertino sulla stampa e il successivo Editto del 26 marzo $1848 .{ }^{45}$

${ }^{42}$ Carteggio tra Giovanni e Carlo Lanza: lettere del 7 e 8 febbraio 1852, in Le carte di Giovanni Lanza, I, 1938, pp. 236-240.

${ }^{43}$ Intervento di Octave Thaon de Revel, Tornata del 7 febbraio 1852, in Atti del Parlamento Subalpino, Discussioni, (VIII) 6 A, 1866, p. 4121.

${ }^{44}$ La Legge del 26 febbraio 1852, $n^{\circ} 1337$, Modificazione all'art. 25 ed abrogazione dell'art. 54 dell'Editto del 26 marzo 1848 sulla libertà della stampa è costituita da un solo articolo. Cfr. Raccolta degli Atti del Governo di S. M. il Re di Sardegna, vol. XX, al $1^{\circ}$ gennaio a tutto dicembre 1852, s.d., pp. 217-218, http://www.dircost.unito.it/root_subalp/1852.shtml ${ }^{45}$ L'art. 28 dello Statuto recita: « La Stampa sarà libera, ma una Legge ne reprime gli abusi. [...]» e l'Editto del 26 marzo 1848, all'art. 25, prevede che "Le offese contro i Sovrani o i Capi dei Governi stranieri saranno punite col carcere estensibile a sei mesi e con multa da lire 100 a 1000.» Regio editto che stabilisce le regole colle quali si abbia da tenere nei Regii Stati l'esercizio della libertà della stampa proclamata dallo Statuto, in Raccolta degli Atti del Governo di S. M. il Re di Sardegna, vol. XVI dal $1^{\circ}$ gennaio a tutto dicembre 1848, 
Effettivamente il diritto di perseguire il reato di oltraggio ai capi di Stato stranieri era stato concesso al pubblico ministero senza l'obbligo di indirizzare al tribunale la richiesta pervenutagli attraverso il canale diplomatico, permettendo di avviare un'azione d'ufficio e costituendo una sorta di censura sui giornali. Il giudizio di questo reato, inoltre, era attribuito ai giudici di carriera anziché ai giurati.

\section{Il contributo di De Foresta al rinnovamento della codificazione del Re- gno di Sardegna}

\subsection{L'apertura del cantiere per l'elaborazione del Codice di procedura civile}

La necessità di disporre di un codice di procedura civile si era posta fin dal 1831 con la nomina della commissione legislativa incaricata della redazione dei nuovi codici sabaudi. In seguito, tra il 1843 e il 1848, due commissioni, dirette dal guardasigilli Barbaroux, lavorarono alla redazione dei codici processuali. ${ }^{46}$ Quella incaricata di realizzare il progetto di codice di procedura civile, tra il 1844 e il 1847, di cui fece parte anche il nizzardo Bartolomeo Bermondi, portò a compimento quattro libri, ma, in seguito all'emanazione dello Statuto e al nuovo ordinamento costituzionale dello Stato, i lavori si arrestarono e nel biennio 1850-52 il codice fu messo da parte.

Con I'avvento del primo Ministero Cavour (04/11/1852-04/05/1855) il tema della codificazione della procedura civile tornò all'attenzione del Governo. Cavour aveva, infatti, in programma l'elaborazione di un Codice di procedura civile ${ }^{47}$ ed avvertiva l'esigenza di promulgarlo in tempi brevi, data la sua incidenza sull'economia del paese, anche se ciò poteva comportare la produzione di un testo imperfetto sul piano tecnico, che, peraltro, sarebbe stato suscettibile di miglioramenti in futuro.

Fu il guardasigilli di Cavour durante la IV Legislatura, Carlo Boncompagni di Mombello ${ }^{48}$, a proporre al Parlamento la nuova formula dell'approvazione 'provvisoria', quando, il 22 marzo 1853, presentò alla Camera dei Deputati il disegno completo di un codice di procedura civile ${ }^{49}$.

Come era avvenuto per i precedenti codici sabaudi, anche al fine di adattare il diritto processuale civile al nuovo ordinamento costituzionale dello Stato, la codificazione subalpina utilizzò quella napoleonica come modello di riferimento. Infatti il Code de Procédure Civile del 1806 rimaneva, nella sostanza, il prototipo

dal $\mathrm{N}^{\circ} 666$ al $\mathrm{N}^{\circ} 864$, s.d., pp. 30 e ss., p. 233 e ss.

${ }^{46}$ Per quanto riguarda i lavori della commissione nominata per completare il codice di procedura civile, cfr. Aimerito, 2008, pp. 196-214

${ }^{47}$ Romeo, III, 1984, pp. 765-766.

${ }^{48}$ Cfr. Traniello, 1969, pp. 695-703; Casana, 2012, pp. 109-173; Casana, 2013, pp. 59-96.

${ }^{49}$ Presentazione del Progetto di legge per l'autorizzazione provvisoria del codice di procedura civile, Tornata del 22 marzo 1853, in Atti del Parlamento Subalpino, Discussioni, (VIII) 4A, 1868, p. 3033. 
più idoneo a dettare una disciplina giuridica organica, completa e territorialmente uniforme.

Un anno dopo il medesimo progetto di legge fu riproposto in Senato dal ministro di Grazia e Giustizia Rattazzi, e fu discusso e approvato, dopo le relazioni delle rispettive Commissioni, dal Senato il 10 giugno 1854 e dalla Camera il 26 giugno ${ }^{50}$. Nell'art. 1 della legge di approvazione del codice, promulgata il 16 luglio 1854 da Vittorio Emanuele II, si stabiliva che:

Il Codice di procedura civile da pubblicarsi in conformità dell'articolo terzo della presente legge è approvato, ed avrà esecuzione cominciando col giorno primo di aprile mille ottocento cinquantacinque. Nella Sessione parlamentare dell'anno mille ottocento cinquantotto sarà posta in deliberazione la revisione di esso codice ${ }^{51}$.

Perciò con la sua entrata in vigore il $1^{\circ}$ aprile 1855 , iniziò un attento monitoraggio della sua applicazione, che doveva prepararne la revisione nella sessione parlamentare del $1858^{52}$.

Infatti, il 24 giugno 1858, De Foresta, ministro di Grazia e Giustizia nel secondo governo Cavour, presentò alla Camera dei Deputati il progetto di legge per l'approvazione - questa volta definitiva - del Codice di procedura civile ${ }^{53}$. Fu soltanto un atto formale, in quanto l'effettiva discussione alla Camera del progetto ministeriale di revisione del codice avvenne nella sessione del 1859, e precisamente il 5 marzo, quando il ministro avviò il dibattito parlamentare con le seguenti parole:

Ho l'onore di presentare alla Camera il progetto di legge per la revisione del codice di procedura civile. Questo Codice è ansiosamente atteso dai privati cittadini, dal fòro e dalla magistratura. Io sono convinto che parecchie delle disposizioni le quali vi sono proposte potranno essere di grande giovamento all'amministrazione della giustizia, e credo pertanto che sia urgente di poterle attuare. Senza intromettermi nell'ordine dei lavori della Camera, mi sia permesso di esprimere un desiderio, quello cioè che l'esame di questo Codice sia direttamente commesso ad una Giunta il più possibile numerosa, affinché fra molti diviso il lavoro riesca più agevole e sia questo spinto colla massima alacrità, per modo che il nuovo Codice possa essere discusso ed approvato ancora in questa Sessione. Ove ciò avvenisse, io credo che la Camera farà cosa utilissima, non solo all'amministrazione della giustizia, ma in generale anche al paese, darà una smentita a quei che credono che sia impossibile di votare un Codice completo in una Assemblea legislativa, e dimostrerà anche con ciò che nulla è impossibile alla buona volontà ed al patriottismo del Parlamento subalpino ${ }^{54}$.

\footnotetext{
${ }^{50}$ Atti del Parlamento Subalpino, Documenti, II, 1869, pp. 1497-1513.

${ }^{51}$ Legge del 16 luglio 1854, N²6, in Raccolta degli Atti del Governo di Sua Maestà il Re di Sardegna, XXIII, Anno 1854, s.d., pp. 117-119.

${ }^{52}$ Marucco, 1996, pp. 3-11.

${ }^{53}$ Per un esame più esaustivo del contributo di Giovanni De Foresta alla promulgazione del codice di procedura civile, si rinvia alla lettura di Aimerito, 2008, pp. 283-319.

${ }^{54}$ Progetto di revisione del codice di procedura civile presentato alla Camera il 5 marzo
} 
Anche questa volta, come per il testo del codice del 1854, il Ministero intendeva procedere rapidamente, e il Giurista propose di affidare l'esame del progetto ad un'apposita giunta composta da un certo numero di deputati, che avrebbero dovuto ripartirsi le singole parti del testo e lavorare in contemporanea ma separatamente all'esame di ciascuna di esse, accelerando così i tempi dell'intero lavoro.

Nel corso della discussione parlamentare, la proposta De Foresta fu accolta, anche se con soluzioni caratterizzate da qualche variante suggerite da Boggio e Biancheri. Quest'ultimo osservò che, se il codice di procedura civile fosse stato sottoposto all'esame degli "uffizi", si sarebbe perso tempo prezioso e propose di affidarne "l'esame preventivo (...) ad una Commissione composta di 21 membri, in correlazione appunto dell'importanza e della mole del progetto, e che questa commissione fosse nominata direttamente dal presidente ${ }^{55}$. La linea governativa, sostenuta dal presidente della Camera Rattazzi, finì dunque con il prevalere: il progetto sarebbe stato esaminato da un'ampia commissione unitaria.

Tuttavia, a causa delle vicende politiche del Regno, segnate dalla guerra e dalle dimissioni di Cavour, cui era subentrato il ministero La Marmora ${ }^{56}$, De Foresta fu esonerato dalla carica di ministro di Grazia e Giustizia e gli subentrò Miglietti (dal 19 luglio 1859 al 21 gennaio 1860), poi sostituito da Giovanni Battista Cassinis ${ }^{57}$. Così il progetto De Foresta fu rivisto da un 'uffizio' governativo. Era, a questo punto, necessario disporre in tempi brevi di un codice definitivo anche nelle nuove Province, obiettivo che la Commissione, per sua stessa ammissione, non fu in grado di raggiungere per mancanza di tempo. La Commissione perciò, non avendo la possibilità di comparare la futura disciplina processuale del Regno di Sardegna con gli altri coevi codici di area germanica (come ad esempio quello di procedura civile austriaca), si concentrò su pochi obiettivi essenziali e terminò i lavori il 16 novembre 1859 durante la VI legislatura.

Il codice del ' 59 - promulgato il 20 settembre, in virtù dei poteri straordinari conferiti al sovrano dalla legge del 25 aprile $1859^{58}$ - rispetto al testo del 1854

1859 dal Ministro di Grazia e Giustizia (De Foresta), in Atti del Parlamento subalpino, Documenti, II, 1875, pp. 667-733.

55 Intervento di Giuseppe Biancheri, Tornata del 5 marzo 1859, in Atti del Parlamento Subalpino, (III) Unico delle discussioni della camera dei deputati 1875, pp. 656-657.

${ }^{56}$ Cfr. Cassetti, Silengo, 1978; Casana, 1997, pp. 44-47; Cavicchioli, 2004, pp. 118-120, 140-210.

${ }^{57}$ Sul profilo giuridico e biografico del personaggio vedasi Caracciolo, 1972, p. 260; D'Addio, 1966, pp. 155, 200 s., 301-307, 314-331; Molfese, 1974, pp. 225, 263, 347, 429; Martone, 1978, http://www.treccani. it/enciclopedia/giovanni-battista-cassinis_(dizionario-biografico)/; Solimano, 2013, pp. 481-482. Sulla rilevanza di Cassinis per la formazione del Codice civile unitario cfr. Solimano, 2003 e Id., 2013, pp. 386-387.

${ }^{58}$ La legge del 25 aprile 1859, $N^{\circ} 3345$, firmata dal guardasigilli De Foresta e da Cavour, fu promulgata nell'imminenza della guerra contro l'Austria. Approvata dalla Camera il 23 e dal Senato il 25 aprile, essa era costituita dai due seguenti articoli: «Art. 1. In caso di 
cercava di rispondere alle numerose istanze di cambiamento, che si erano delineate nel quinquennio della sua applicazione provvisoria ${ }^{59}$. Infatti il Ministero di Grazia e Giustizia, durante il periodo in cui fu retto da De Foresta, si era dimostrato ampiamente disposto a prendere in considerazione queste istanze provenienti dal mondo della pratica forense ed aveva dato la sua disponibilità ad approfondire il discorso sul piano tecnico giuridico.

Così il nuovo codice rappresentava il frutto della raccolta di dati sull'andamento dei giudizi civili che il Giurista aveva promosso a partire dal settembre del 1855, ma anche nel periodo in cui aveva retto per la prima volta il dicastero di Grazia e Giustizia. Proprio in quegli anni era stata condotta a termine, sotto la sua guida, la ponderosa Statistica giudiziaria civile, commerciale e del contenzioso amministrativo degli Stati sardi per gli anni 1849-1850 ${ }^{60}$. De Foresta era, in effetti, convinto che queste statistiche potessero fornire strumenti utili ad avvicinare le procedure alle indicazioni provenienti dai dati raccolti presso gli uffici giudiziari, nei quali aveva favorito l'istituzione di apposite banche-dati.

Perciò, nel 1855, aveva avviato un'attività di monitoraggio dello svolgimento del processo civile, affinché dalla registrazione dei modi in cui venivano risolte le controversie civili nei Tribunali e nelle Corti venissero aiuti concreti al rinnovamento legislativo. Su questo tema, così scriveva nella sua relazione alla Camera:

Ed appunto perché non andassero perduti gl'insegnamenti quotidiani della pratica fu mio pensiero, appena le nuove leggi processuali furono poste in osservanza, di ordinare che tutte le questioni, a cui le medesime dessero luogo e che si presentassero alla decisione delle Corti e Tribunali, fossero per riassunto consegnate in uno speciale registro, nel quale si dovesse far cenno non pure delle insorte controversie, ma anche del modo con cui verrebbero risolte, e che un estratto di tale registro fosse ogni trimestre al Ministero trasmesso. Venne così a formarsi una statistica, che chiamerò sperimentale, la quale poté essere con molto frutto consultata. Avvicinandosi poi il tempo dalla legge prefisso per la revisione del

guerra coll'Impero d'Austria, e durante la medesima, il Re sarà investito di tutti i poteri legislativi ed esecutivi, e potrà, sotto la responsabilità ministeriale, fare per semplici Decreti Reali tutti gli atti necessari alla difesa della Patria e delle nostre Istituzioni. Art. 2. Rimanendo intangibili le Istituzioni costituzionali, il Governo del Re avrà la facoltà di emanare disposizioni per limitare provvisoriamente, durante la guerra, la libertà della stampa e la libertà individuale. Ordiniamo che la presente, munita del Sigillo dello Stato, sia inserta nella raccolta degli atti del Governo, mandando a chiunque spetti di osservarla e di farla osservare come legge dello Stato»: Raccolta degli Atti del Governo di Sua Maestà il Re di Sardegna, XXVIII, Anno 1859, s.d., pp. 391-392.

${ }^{59}$ Secondo le valutazioni del Commentario Mancini-Pisanelli-Scialoja, numerosi miglioramenti e semplificazioni di alcune procedure, come l'audizione di testimoni, nonché attenuazioni del rigore di alcune disposizioni del testo del 1854, furono introdotti dal nuovo Codice del 1859. In proposito, cfr. Aimerito, 2008, pp. 295-297.

${ }^{60}$ Statistica giudiziaria civile, commerciale e del contenzioso amministrativo degli Stati sardi per gli anni 1849 - 1850, 1852. 
suddetto Codice, io mi rivolsi alle Corti, ai tribunali, ai giudici di mandamento, ai capi del Ministero pubblico, agli avvocati e procuratori dei poveri ed agli avvocati e procuratori esercenti, e, facendo un appello alla loro dottrina e alle pratiche loro cognizioni, li richiesi di voler additare le imperfezioni che l'esperienza avesse nel nuovo sistema di procedura civile rilevate, e di suggerire i miglioramenti da introdurvisi ${ }^{61}$.

Il Codice di procedura civile del $1859 \mathrm{fu}$, comunque, un'innegabile attuazione di questa tendenza liberale, che si affermò anche attraverso un allontanamento dal paradigma napoleonico. Né ciò può essere attribuito a pressioni di natura corporativa, soprattutto perché le argomentazioni addotte - nel corso della fase preparatoria del nuovo codice, dai professionisti fautori delle innovazioni e poi effettivamente trasferite nel dettato codicistico - sembrano mosse dalla sincera volontà di fondare un sistema processuale migliore piuttosto che da quella di realizzare un codice modellato esclusivamente sugli interessi dei magistrati.

\subsection{La revisione del Codice penale}

Fino al 1859 nel Regno di Sardegna vigeva il Codice penale albertino del 1839, fedele al Codice penale napoleonico del 1810, anche se la presenza di alcuni elementi - come la previsione di sanzioni contro il suicidio, l'inclusione di reati come l'aborto, la violenza carnale e l'adulterio tra i crimini contro lo Stato ${ }^{62}$ nonché il mantenimento dei reati contro la religione - lo rendeva ancora più obsoleto del modello napoleonico.

II 1840, l'anno successivo all'emanazione del Codice penale, vide la pubblicazione del Codice penale militare e di un regolamento di procedura penale, mentre solo nel 1847 venne pubblicato un Codice di procedura penale.

Perciò, nel "decennio di preparazione" dell'unificazione italiana, furono posti in essere da Rattazzi e da De Foresta - i due guardasigilli che si succedettero durante i Ministeri Cavour - importanti progetti di riforma della legislazione e della macchina giudiziaria del regno di Sardegna. Tuttavia questi progetti si arenarono in estenuanti discussioni parlamentari senza approdare ad alcun risultato concreto, come dimostra il dibattito sul progetto di codice penale di De Foresta, che esamineremo in questo paragrafo.

Dopo l'armistizio di Villafranca dell'11 luglio1859, che segnò la fine della Seconda Guerra d'Indipendenza e le dimissioni di Cavour dal governo, Rattazzi entrò a far parte del gabinetto La Marmora come ministro dell'Interno. Grazie alla Legge n. 3345 del 25 aprile 1859, sottoscritta da De Foresta, il governo ottenne poteri straordinari, che gli consentirono di governare senza il consenso del Parla-

\footnotetext{
${ }^{61} \mathrm{G}$. De Foresta, Relazione sul progetto di revisione del codice di procedura civile presentato alla Camera il 5 marzo 1859, Atti del Parlamento subalpino, Discussioni, (III) Unico delle discussioni della camera dei deputati 1875, p. 667.

${ }^{62}$ Codice penale per gli Stati di S. M. il Re di Sardegna, 1839, pp. 157 e ss.
} 
mento ${ }^{63}$. Rattazzi, utilizzando anche la Legge ${ }^{\circ} 3702$ del 23 ottobre 1859, da lui stesso emanata, poté così iniziare un'opera di riorganizzazione amministrativa e legislativa, riuscendo a far promulgare anche tre nuovi codici (penale, di procedura penale, di procedura civile $\left.{ }^{64}\right)$.

Nel quadro di questa revisione complessiva dei codici di Carlo Alberto, il Codice penale fu rivisto e promulgato nella sua nuova versione il 20 novembre 1859, entrando in vigore il 10 maggio 1860, insieme al nuovo Codice di procedura penale.

Le modifiche introdotte nel Codice penale del 1859 portarono all'abolizione dei reati contro la religione, alla limitazione della pena di morte ed alla mitigazione delle pene per i reati politici.

Il Codice penale piemontese del 1859 fu esteso poi al resto della penisola all'indomani dell'unità d'Italia. Tuttavia, la codificazione penale sabauda non entrò in vigore nei territori dell'ex-Granducato di Toscana, dove continuò ad essere applicato il Codice penale toscano del 1853, che era stato tra l'altro emendato della pena di morte dal Governo provvisorio toscano nel 1859. Anche nei territori dell'ex-Regno delle Due Sicilie, il Codice sabaudo dovette essere integrato con alcune disposizioni di derivazione dal vecchio Codice borbonico del 1819, erede della codificazione murattiana del 1812.

Per il resto dei territori italiani, tuttavia, il testo, come modificato nel 1859, costituì la legislazione penale unitaria italiana fino all'emanazione del cosiddetto Codice Zanardelli del 1889.

Dopo questa panoramica storica e giuridica, è ora possibile esaminare l'azione svolta alla Camera subalpina da De Foresta - prima come deputato, poi come guardasigilli - per effettuare una riforma del diritto penale considerata urgente e inevitabile dalla maggioranza dei parlamentari. Quindi torniamo al punto di partenza, cioè al Codice del 1839, che, introducendo i principi della non retroattività della legge penale e del favor rei, rappresentava un indubbio progresso rispetto alla precedente legislazione criminale sabauda risalente alle Leggi e Costituzioni di Sua Maestà del 1770, ma presentava due gravi difetti.

Il primo era quello di essere fortemente debitore ai codici penali napoleonici sia per la limitazione della libertà decisionale dei magistrati ${ }^{65}$ sia per il valore deterrente attribuito alla pena di morte che veniva comminata per un numero molto rilevante di fattispecie, ivi compresi i crimini di lesa maestà e quelli contro la religione di Stato, come il sacrilegio.

Il secondo era quello della sua obsolescenza, trattandosi di norme stabilite dieci anni prima dell'entrata in vigore dello Statuto albertino, che in teoria avrebbe dovuto comportare un radicale rinnovamento di tutta la normativa penale.

Quindi non stupisce che nella tornata del 27 marzo 1856, il giorno dopo l'inizio

\footnotetext{
${ }^{63}$ Dezza, 2009, pp. IX-XXXII.

${ }^{64}$ Per quanto riguarda la pubblicazione del Codice di procedura civile, cfr. il precedente paragrafo 4.1

${ }^{65}$ Per l'interdizione della possibilità di aumentare o diminuire la pena edittale.
} 
della discussione di un progetto sul Riordinamento dell'ordine giudiziario e del Ministero pubblico ${ }^{66}$, presentato da De Foresta, il deputato della sinistra Angelo Brofferio ${ }^{67}$, rimarcando il ritardo con cui il Governo agiva, poiché era da sei anni che si promettevano riforme della giustizia penale senza poi realizzarle, affermasse:

II signor guardasigilli ammette la necessità della riforma da me proposta in ordine ai giudizi criminali, ed io gli so buon grado della sua schietta dichiarazione. Ma (egli soggiunge) si può forse improvvisare una riforma dei Codici così su due piedi? Signori, è dal 1850 che io vado raccomandando queste riforme, ed è dal 1850 che i ministri vanno promettendo di farle. Non si tratta d'improvvisare quando si hanno sei anni di tempo a meditare. Del resto le correzioni che io propongo non portano la necessità di sovvertire tutto il Codice; si tratta di emendare gli articoli del Codice penale che portano eccessive pene e di cancellare gli articoli del Codice di procedura criminale che sono ripugnanti allo Statuto, coordinando gli uni e gli altri tra loro; questo è lavoro grave e serio, ma non è opera immensa, come si vorrebbe far credere. Coloro che sono versati in queste materie con trenta giorni di lavoro possono provvedere alla doppia esigenza della libertà e della giustizia. Colla volontà, collo studio e colla costanza si superarono difficoltà molto più gravi che non è questa ${ }^{68}$.

Le suddette considerazioni furono fatte proprie, durante la tornata stessa, dal deputato Lorenzo Valerio, il quale rappresentò alla Camera la necessità che essa esprimesse «il suo voto per una pronta riforma del Codice di procedura criminale per la preventività del carcere e del Codice penale, specialmente per ciò che riguarda la pena della morte ${ }^{69}$.

La proposta, presentata formalmente da Valerio e ampiamente discussa nei due giorni successivi, era incentrata su tre elementi: l'eccessiva durata della detenzione preventiva (a volte fino a tre anni), che, sulla base del codice di procedura penale in vigore, era applicata su vasta scala; le cattive condizioni di detenzione nelle carceri, che il deputato definiva «luoghi di infezione morale e fisica»; l'applicazione troppo frequente della pena capitale ${ }^{70}$.

\footnotetext{
${ }^{66}$ Atti del Parlamento Subalpino, Sessione 1857 (V Legislatura) dal 7 gennaio al 16 luglio 1857, Documenti, I, Roma, Eredi Botta, 1872, p. 149. Si rinvia anche al vol. II dei Documenti della sessione 1855-1856, pp. 945-989, dove sono riportati il progetto di Giovanni De Foresta presentato alla Camera il 26 marzo 1856 e la relazione della Commissione composta da De Viry, Zirio, Tecchio, Arnulfo, Capriolo, Cassinis, e Astengo, relatore (16 giugno 1856).

${ }^{67}$ Sulla biografia e l'attività politica e letteraria di Angelo Brofferio vedi Bottasso, 1972, pp. 408-413.

68 Intervento di Angelo Brofferio, Tornata del 27 marzo 1856, in Atti del Parlamento Subalpino, Discussioni, (IV) 2 A, 1872, pp. 1169-1170.

${ }^{69}$ Intervento di Lorenzo Valerio, Tornata del 27 marzo 1856, in Atti del Parlamento Subalpino, Discussioni, (IV) 2 A, 1872, p. 1172.

${ }^{70}$ Intervento di Lorenzo Valerio, Tornata del 28 marzo 1856, in Atti del Parlamento Subal-
} 
La risposta del ministro della Giustizia fu molto misurata, ma dettagliata: mentre la questione della detenzione preventiva era già stata in qualche modo disciplinata dall'art. 6 legge del 23 giugno $1854^{71}$, che introduceva modificazioni al codice penale vigente, una commissione ministeriale stava lavorando ad una revisione integrale del Codice penale; De Foresta invitò quindi la Camera ad attendere la presentazione del progetto da essa redatto ${ }^{72}$.

Perciò il 29 marzo l'esame dell'ordine del giorno si concluse con l'approvazione della mozione del deputato Buffa ${ }^{73}$, che richiamava il Governo a "completare le riforme iniziate affine di mettere le diverse parti della nostra legislazione penale in armonia fra loro e collo spirito degli ordini costituzionali ${ }^{74}$.

A seguito di queste richieste il ministro della Giustizia, l'anno successivo e precisamente il 9 gennaio 1857, presentò un progetto di revisione di alcune disposizioni del codice penale albertino, che vennero poi in buona parte riprese dal Codice penale fatto approvare due anni dopo da Rattazzi, diventato nel 1859 ministro dell'Interno nel primo governo Lamarmora. Nella sessione del 1857 l'iter parlamentare del progetto intitolato Modificazioni al codice penale non andò oltre la presentazione al Senato, il 31 marzo, del testo approvato dalla Camera, dove la discussione degli articoli del codice si era protratta dal 17 al 25 marzo, data in cui fu approvato l'intero progetto con 108 voti favorevoli e 15 contrari $^{75}$.

II progetto De Foresta consisteva in appena 7 articoli, mirati però ad apportare sostanziali modificazioni al codice albertino del 1839 soprattutto sul piano sanzionatorio ${ }^{76}$.

Tale disegno di legge limitava fortemente l'applicazione della pena di morte che veniva convertita nei lavori forzati a vita per tutti i «reati che non hanno avuto per conseguenza immediata la morte di alcuna persona» (con la sola eccezione dei reati di attentato contro la persona del Re o contro un membro della famiglia reale) e per l'infanticidio. La pena prevista nel Codice penale albertino per la bestemmia diminuiva, passando dai lavori forzati a tempo a un massimo di tre mesi di carcere. Inoltre l'art. 5 consentiva ai giudici di abbassare tutte le pene di

pino, Discussioni, (IV) 2 A, 1872, p. 1177.

${ }^{71}$ Legislazione del Regno di Sardegna anno 1854 legge n. 1730. http://www.dircost.unito. it/root_subalp/1854.shtml

72 Intervento di Giovanni de Foresta, Tornata del 28 marzo 1856, in Atti del Parlamento Subalpino, Discussioni, (IV) 2 A, 1872, pp. 1179-1180.

${ }^{73}$ Sulla personalità politica di Domenico Buffa cfr. Franzoni Gamberini, 1972, pp. 803-806. ${ }^{74}$ Intervento di Domenico Buffa, Tornata del 29 marzo 1856, in Atti del Parlamento Subalpino, Discussioni, (IV) 2 A, 1872, p. 1202.

${ }^{75}$ Atti relativi al progetto Modificazioni al Codice penale (presentazione del progetto da parte di De Foresta alla Camera, relazione della Commissione della Camera, relazione del ministro in Senato sul progetto approvato dalla Camera): Atti del Parlamento Subalpino, Discussioni, (IV) 2 A, 1873, pp. 153-160.

${ }^{76}$ Tornata del 17 marzo 1857, in Atti del Parlamento Subalpino, Discussioni, (IV) 2 A, 1873, pp. 1041-1042. 
un grado, tenuto conto delle circostanze del reato e l'art. 6 ammetteva la prescrizione per ogni tipo di reato, interdicendo l'azione penale dopo 20 anni dalla commissione del reato e la pena dopo 30 anni dalla pronuncia della sentenza. Infine il disegno di legge abrogava una serie di disposizioni del Codice penale (in particolare gli artt. 163, 583, 612, 728 e 730), che vietavano ai magistrati di considerare la presenza di attenuanti in determinate fattispecie (ad esempio per il parricidio o l'avvelenamento). II progetto De Foresta venne esaminato da una Commissione, costituita pressoché interamente da avvocati, che, in sede referente, valutarono positivamente la legge proposta dal guardasigilli, definendole «buona nelle sue poche disposizioni». Tuttavia, essendosi limitata all'esame dei sette articoli del progetto ministeriale senza entrare nel merito delle pene minori, la Commissione esprimeva altresì l'augurio che il Ministero non si fermasse a questo "primo passo» e sollecitasse "una più ampia e ponderata revisione di tutta la scale penale» ${ }^{77}$.

Nella relazione della Commissione parlamentare si faceva notare inoltre come lo scopo del progetto di legge fosse quello di ridurre il numero dei reati puniti con la pena di morte, perché l'applicazione troppo frequente diminuisce «la terribilità e perciò l'efficacia di un supplizio destinato soprattutto a colpire la immaginazione degli uomini». Occorreva dunque limitarla ai casi più gravi e perciò a quelli che hanno "come conseguenza immediata la morte della persona offesa ${ }^{78}$.

La sola modifica sostanziale apportata dalla Commissione al progetto del Ministero riguardò la prescrizione dei reati: abrogava l'art. $158^{79}$ del Codice penale (cancellando il secondo capoverso dell'art. 6 del progetto ministeriale) e da ciò conseguiva che l'ammissione della prescrizione per ogni genere di reati e la designazione del giorno da cui decorreva il termine della prescrizione avrebbero dovuto essere applicate anche ai reati anteriori alla pubblicazione della nuova legge, senza distinguere tra reati commessi prima o dopo l'attuazione del Codice ${ }^{80}$.

Infine, in accordo con i principi dell'umanità e della giustizia erano, secondo la Commissione parlamentare, anche le disposizioni dell'art. 5, per cui, in presenza di circostanze attenuanti, la pena veniva diminuita di un grado «senza pregiudizio delle maggiori diminuzioni prescritte o permesse da esso Codice».

Il disegno di legge fu discusso a partire dalla tornata del 17 marzo 1857, in cui il

\footnotetext{
${ }^{77}$ Relazione presentata alla Camera il 27 febbraio 1857 dalla Commissione composta dai deputati Livio Benintendi, Angelo Brofferio, Riccardo Sineo, Luigi Melegari, Carlo Pezzani, Giacomo Astengo, Sebastiano Tecchio (relatore), in Atti del Parlamento Subalpino, Documenti, I, 1872, pp. 155-156.

${ }^{78}$ Atti del Parlamento Subalpino, Documenti, I, 1872, p. 155.

${ }^{79}$ Art.158 «Le azioni penali e le pene per reati anteriori, per cui a termini della legge allora vigente non fosse ammessa la prescrizione, incomincieranno a prescriversi dal giorno dell'osservanza del presente Codice, ed a norma di quanto è da questo disposto.», Codice penale per gli Stati di S. M. il Re di Sardegna, 1839, p. 45.

${ }^{80}$ Relazione fatta alla Camera il 27 febbraio 1857 dalla Commissione parlamentare, in Atti del Parlamento Subalpino, Documenti, I, 1872, p. 156.
} 
deputato Luigi Genina ${ }^{81}$, dopo aver osservato che «i più gravi reati di grassazione con omicidio, o consumati, o per lo meno tentati» erano aumentati, passò in rassegna i 7 articoli di cui esso consisteva, prendendo le mosse dalle ragioni che in genere motivano le riforme di un codice penale: «o per porle in armonia colle cangiate forme governative, ovvero per modificarle in modo che esso si renda conforme ed ai progressi della scienza del diritto ed ai più miti costumi della società ${ }^{82}$.

Nel Regno di Sardegna si era evidentemente verificata la prima circostanza a cui Genina si riferiva: lo Statuto Albertino del 1848 aveva mutato la forma di governo dello Stato trasformandolo in una monarchia rappresentativa. Ciò non poteva non influenzare il diritto penale e rendeva quindi necessario modificare il codice penale per uniformarlo ai principi affermati nello Statuto, che, come ricordava Genina, erano la responsabilità ministeriale, l'elemento elettivo, l'inviolabilità del domicilio e la libertà di associazione. La modifica del Codice penale era inoltre resa necessaria dai cambiamenti sociali e dai progressi della scienza giuridica, anche se, come puntualizzava il deputato, il guardasigilli non aveva ritenuto opportuno procedere ad una riforma radicale.

Il discorso del penalista Genina distingueva inoltre tra omicidio consumato, per il quale la pena capitale doveva essere mantenuta, e omicidio tentato, per il quale i lavori forzati a vita sarebbero stati sufficienti.

Genina peraltro riteneva giusta l'abolizione della pena capitale soltanto per alcune delle fattispecie a cui il Codice vigente la comminava, ad eccezione dell'incendio di edifici pubblici adibiti a riunioni, quand'anche non vi fossero vittime (art. 699) ${ }^{83}$. In quanto alla rapina a mano armata accompagnata da omicidio o da tentato omicidio o da ferite e aggressioni comportanti la morte (art. 643, primo comma) $)^{84}$, il deputato si dichiarava d'accordo con l'abolizione della pena capitale in quest'ultimo caso, ma esitava ad approvarne l'abolizione quando la rapina fos-

\footnotetext{
${ }^{81}$ Luigi Genina (Mezzenile-Torino, 1806 - Torino,1876), laureato in Giurisprudenza e deputato al parlamento subalpino dalla I alla VI legislatura senza soluzione di continuità; fu avvocato, giudice e consigliere di Stato. Nell'anno accademico 1846-1847, gli fu affidato 'insegnamento di Diritto penale nella Facoltà di legge di Torino. Cfr. Ferrero, 2016, p. 12; Pene Vidari, 2013, pp. 1-58.

${ }^{82}$ Intervento di Luigi Genina, Tornata del 17 marzo 1857, in Atti del Parlamento Subalpino, Discussioni, (IV) 2 A, 1872 p. 1042.

${ }^{83}$ Art. 699: «Chiunque avrà volontariamente appiccato il fuoco a pubbliche Chiese, a Palazzi Reali, ovvero ad edifizi che servono a pubbliche riunioni e durante il tempo delle medesime, sia che questi edifizi appartengano o non appartengano all'autore dell'incendio, sarà punito colla morte. ». Codice penale per gli Stati di S. M. il Re di Sardegna, 1839, p. 211.

${ }^{84}$ Art. 643: "La depredazione commessa in qualsivoglia luogo con alcuna delle circostanze indicate nei numeri seguenti constituisce la grassazione: 1 . Se è accompagnata da omicidio, ancorché solo tentato, o da ferite, percosse o mali trattamenti tali che costituiscano di per sé un crimine. [...]». Codice penale per gli Stati di S. M. il Re di Sardegna, 1839, p. 192. Cfr. Traverso, 2019b, pp. 293-327.
} 
se accompagnata da omicidio anche se soltanto tentato ${ }^{85}$.

Giovanni de Foresta fu in seguito chiamato in causa da Sebastiano Tecchio, relatore della Commissione parlamentare esaminatrice del progetto, il quale fece notare come le osservazioni di Genina circa l'aumento dei «più gravi reati di grassazioni con omicidio, o consumati, o per lo meno tentati» fossero errate, chiedendo al guardasigilli di portare a conoscenza della Camera le statistiche in suo possesso sull'argomento, a conferma di quanto egli asseriva ${ }^{86}$.

Perciò nella tornata del 19 marzo '57 il Giurista intervenne, precisando subito di non voler anticipare la discussione dei singoli articoli, dal momento che il progetto era in linea di massima accettato da tutti i deputati che fino a quel momento si erano espressi in proposito. Intendeva soltanto fornire chiarimenti circa «alcune speciali censure» che Genina aveva avanzato in merito al progetto e innanzitutto rispondere alla sua affermazione che i crimini erano in aumento.

De Foresta attraverso i dati statistici, di cui disponeva per il periodo 1853-56, illustrò l'evoluzione dei crimini: dai 2036 crimini commessi nel 1853, diventati 2264 nel 1854, si era passati a 1791 nel 1855, decremento che era continuato anche nel '56, nonostante il ministro non fosse in possesso di informazioni complete rispetto a quest'ultimo anno. Altrettanto confortanti erano i dati relativi al numero di detenuti presenti nelle carceri di Torino e nel distretto della Corte d'Appello di Torino: nelle prime, per esempio, si era passati dai 960 detenuti del 1855 ai 695 del 1856 e ai 545 del $1857^{87}$.

Si dichiarò poi convinto circa l'opportunità della presentazione di questa proposta di legge, ricordando ai deputati come essa fosse attribuibile principalmente all'iniziativa parlamentare, in quanto la Camera, in seguito alle discussioni avviate - nelle sedute dei 26, 27, 28 e 29 marzo dell'anno precedente - dalle interpellanze dell'onorevole Brofferio, aveva essa stessa invitato il Governo a presentare un disegno di legge per le riforme urgenti del sistema penale.

De Foresta, tuttavia, tenne a precisare che:

[ ] i reati non scemano, né s'impediscono colle pene rigorose, ma bensì col reprimere, quanto è possibile, l'ozio, il vagabondaggio, e col cercare fino ad un certo punto di scemare il proletarismo, sviluppando il benessere materiale e morale delle popolazioni, e promovendone l'istruzione: ed è appunto perché il Governo non trascura tal suo dovere, che il numero dei reati decresce. La severità delle pene produce anzi un contrario effetto, perché essa facilita l'impunità dei delinquenti; [ ] Quanto è meno probabile l'impunità, altrettanto più rare diventano le infrazioni della legge: epperò la severità della pena può contribuire ad accrescerle appunto

\footnotetext{
${ }^{85}$ Intervento di Luigi Genina, Tornata del 17 marzo 1857, in Atti del Parlamento Subalpino, Discussioni, volume (IV) 2A, 1873, p. 1044.

${ }^{86}$ Intervento di Sebastiano Tecchio, Tornata del 17 marzo 1857, in Atti del Parlamento Subalpino, Discussioni, volume (IV) 2A, 1873, p. 1046.

${ }^{87}$ Intervento di G. de Foresta, Tornata del 19 marzo 1857, in Atti del Parlamento Subalpino, Discussioni, (IV) 2A, 1873, p. 1072.
} 
perché più difficile diventa la loro punizione ${ }^{88}$.

Il ministro espose quindi alla Camera i principi generali che avevano ispirato il progetto in discussione. Il primo era il mantenimento della pena di morte soltanto per i reati che avevano come "conseguenza immediata» la morte di una persona, come recitava l'art. 1 del progetto. Su questo punto, infatti, era in disaccordo con le argomentazioni di Genina che, come si è ricordato, proponeva alcune eccezioni. De Foresta, invece, ribadiva che la misura della pena doveva essere stabilita in base al dolo e al danno sociale arrecato dal crimine: se la pena capitale veniva inflitta per l'omicidio consumato (per esempio, a chi aveva causato la morte di persone appiccando un incendio), si doveva infliggere una pena minore a chi nella medesima circostanza non aveva causato la morte di alcuno, qualsiasi fossero state le sue intenzioni ${ }^{89}$.

Di conseguenza occorreva diminuire la pena di un grado ogni volta che l'omicidio non fosse stato consumato e quindi punire il tentato omicidio con i lavori forzati a vita:

Qualunque possa essere il dolo di colui che abbia attentato alla vita di un altro, sarà sempre incontestabile che il reato sarà minore, perché minore è il danno sociale, quando all'intenzione non corrispose l'effetto; quando, cioè, l'omicidio non fu consumato. Epperciò, ritenendo noi per la pena massima quella della morte, e questa infliggendo per l'omicidio consumato, di necessità, per proporzionarla, dovevamo diminuirla di un grado e limitarla ai lavori forzati tuttavolta che non sia seguita la morte d'alcuno ${ }^{90}$.

A differenza dell'onorevole Genina, De Foresta era inoltre convinto che all'art. 1 del progetto fosse necessario specificare che la morte deve essere la conseguenza «immediata» del reato. Per stabilire se comminare o meno la pena capitale, occorreva infatti distinguere questa circostanza da quella in cui si era provato che la morte avvenuta nei quaranta giorni successivi al compimento del reato era dovuta, oltreché al reato, anche o all'imperizia del medico che aveva curato il ferito $\mathrm{o}$ alle condizioni di salute di questi.

In quanto all'art. 2 del progetto in questione, che puniva i reati contemplati negli artt. 554, 571 ${ }^{91}$ del Codice penale con i lavori forzati a vita, De Foresta, per la medesima ragione - e cioè per una questione di proporzionalità tra pena e reato - non era d'accordo con Genina, il quale riteneva che l'infanticidio dovesse

\footnotetext{
${ }^{88}$ Atti del Parlamento Subalpino, Discussioni, (IV) 2A, 1873, pp. 1072-1073.

${ }^{89}$ Atti del Parlamento Subalpino, Discussioni, (IV) 2A, 1873, p. 1073.

${ }^{90}$ Atti del Parlamento Subalpino, Discussioni, (IV) 2A, 1873, p. 1073.

${ }^{91}$ Art. 554. "Se però dal complesso delle circostanze risulti, che l'abbandono dell'infante non poteva avere altro oggetto che la morte del medesimo e sia questa avvenuta in conseguenza dell'abbandono, il colpevole è punito come reo d'infanticidio.» Art. 571. "L'omicidio volontario di un infante di recente nato, è qualificato infanticidio.» Codice penale per gli Stati di S. M. il Re di Sardegna, 1839, pp. 165-166, 170.
} 
essere punito con la pena capitale. Secondo il ministro di Grazia e Giustizia, invece, l'infanticidio costituiva, sia per l'intenzione delittuosa dell'azione sia per il danno sociale, un reato meno grave dell'omicidio di un adulto. Dunque omicidio e infanticidio non erano punibili con la medesima pena, anche per il fatto che, aggiungeva De Foresta, l'infanticidio era spesso determinato da «cause prepotenti», cioè compiuto in condizioni sociali di povertà o in difesa dell'onore della donna o della famiglia.

Ora io chieggo se nell'uccisione di un infante appena nato vi sia la stessa immoralità dell'azione, lo stesso dolo, lo stesso danno che nell'uccisione di una persona adulta. Sembrami che ciò non possa sostenersi in guisa veruna, giacché l'infante che si trova appena sul limitare della vita, di cui non ha, dirò così, ancora preso possesso, che non ha alcuna conoscenza della società e non è da questa conosciuto, questi non è certo nella condizione in cui trovasi una persona adulta che ha già coscienza dell'esistenza sua, che è in possesso della vita, e che già costò per essere allevata ed educata e sacrifizi e assistenze e tutto ciò che la società provvede alle persone adulte. [...] Ditemi, in grazia, se nel primo caso voi foste colti dallo stesso ribrezzo che vi commosse all'udire l'annuncio di un omicidio o di un assassinio. Certo che no. E ciò perché? Perché la coscienza pubblica trova in un reato molto maggiore gravità che nell'altro, perché nel'omicidio di una persona adulta la coscienza pubblica vede un gran danno sociale, e nell'altro invece vede bensì un male, un reato da punire, ma non così grave, non così intenso il pericolo sociale. Ora, se i due reati non sono uguali e per l'immoralità dell'azione e pel danno sociale, uguale non deve essere la pena. A questo aggiungasi che nella maggior parte dei casi l'infanticidio è sempre determinato da cause prepotenti, per cui, se non si fa luogo alla scusa totale, almeno grandemente scema la imputabilità dell'agente ${ }^{92}$.

A proposito della disposizione contenuta nell'art. 5 della proposta di legge - In tutti i casi preveduti dal Codice penale, quando concorrano circostanze attenuanti, la pena sarà diminuita di un grado, senza pregiudizio delle maggiori diminuzioni prescritte o permesse da esso Codice - De Foresta affermava di considerarla «la più pregievole e la più utile», perché consentiva di conseguire il fine che la legge si proponeva, cioè una giusta proporzione fra i delitti e le pene. Questo principio rivestiva, dunque, la più grande importanza per il ministro: nel suddetto articolo, infatti, si riconosceva al giudice la possibilità di valutare altre circostanze attenuanti, oltre a quelle già previste dal Codice, mentre l'onorevole Genina era assolutamente contrario a questa modifica del Codice penale.

Il confronto fra i pareri dei due parlamentari consente di constatare come si riproponesse il dibattito relativo all'ampiezza da lasciarsi alla discrezionalità del giudice nel valutare le circostanze attenuati, e conseguentemente nel punire il crimine.

\footnotetext{
${ }^{92}$ Intervento di De Foresta, Tornata del 19 marzo 1857, in Atti del Parlamento Subalpino, Discussioni, (IV) 2A, 1873, p. 1074.
} 
De Foresta era favorevole a riconoscere ai giudici una più ampia libertà d'azione nel valutare le circostanze afferenti al reato, non soltanto perché così facendo si seguivano "principii già sanciti dal Codice stesso, e che sono il cardine su cui fondasi la misura della proporzionalità della pena», ma anche perché si trattava di riconoscere che non tutte le circostanze attenuanti - «infinite, svariatissime nella loro natura» - potevano essere previste dal legislatore ${ }^{93}$.

Decisamente contrario all'art. 5 fu invece Genina perché la considerazione delle circostanze attenuanti, così come era in esso proposta, avrebbe comportato la diminuzione di un grado dell'intera scala penale del Codice in vigore e un ritorno all'arbitrio del giudice ${ }^{94}$.

Il penalista argomentava la sua posizione ricordando come, prima dei progressi del diritto penale, il potere del giudice nel determinare le pene fosse "immenso», come ciò avesse trovato un'alternativa di segno opposto nel sistema delle 'pene fisse' del Code pénal del 1791. Si era poi giunti ad un sistema intermedio, quello adottato dal Codice penale napoleonico del 1810 e dal Codice penale del Regno di Sardegna, lasciando al giudice la possibilità di adeguare la pena al grado di imputabilità dell'autore del reato.

Se era vero che, non potendo in alcun modo prevedere "certe circostanze soggettive personali», la legge doveva lasciarne l'apprezzamento al potere discrezionale del giudice, essa doveva però stabilire quali circostante oggettive potessero essere considerate attenuanti e in che misura comportassero un aumento o una diminuzione della pena. La dottrina, affermava Genina, concordava sul fatto che «quanto si può fare con legge in materia penale, non bisogna lasciarlo al giudice ${ }^{95}$. Perciò occorreva impedire che l'affidamento al giudice della valutazione delle circostanze attenuanti significasse un ritorno al sistema dell'arbitrio dei giudici tipico dell'Antico Regime. In effetti, nell'applicare pene meno severe considerando come attenuanti alcune circostanze oggettive, i magistrati avrebbero potuto sostituirsi in parte al legislatore e persino al sovrano "graziando» l'imputato in virtù di quella stessa valutazione ${ }^{96}$.

Occorre, comunque, rilevare che la contrarietà di Genina all'emendamento contenuto nell'art. 5 era motivato anche da un'altra preoccupazione: adottandolo si sarebbero diminuite le pene dei reati più gravi di ben due gradi, l'uno in base a quanto stabilito dall'art. 1, l'altro grazie all'intervento del giudice consentito dall'art. $5^{97}$.

Le disposizioni relative alla prescrizione, contenute nell'art. 6 della proposta di legge - La prescrizione in materia penale è ammessa per ogni genere di reati.

\footnotetext{
${ }_{93}$ Atti del Parlamento Subalpino, Discussioni, volume (IV) 2A, 1873, p. 1074.

${ }^{94}$ Intervento di Luigi Genina, Tornata del 18 marzo 1857, in Atti del Parlamento Subalpino, Discussioni, (IV) 2A, 1873, p. 1052.

${ }^{95}$ Atti del Parlamento Subalpino, Discussioni, volume (IV) 2A, 1873, pp. 1050-1051.

${ }^{96}$ Atti del Parlamento Subalpino, Discussioni, volume (IV) 2A, 1873, p. 1051.

${ }^{97}$ Atti del Parlamento Subalpino, Discussioni, volume (IV) 2A, 1873, p. 1050.
} 
Ove il Codice penale non istabilisce un termine più breve, avranno luogo le norme seguenti: $1^{\circ}$ L'azione penale è prescritta col termine d'anni venti dal giorno del reato, 0 , se v'ebbe processo, dall'ultimo atto di questo; $2^{\circ}$ La pena è prescritta col termine di anni trenta dal giorno della sentenza - furono giustificate dal ministro della Giustizia attraverso una serie di motivazioni. Innanzi tutto egli ricordò quelle addotte dai filosofi e dai criminalisti: il passare del tempo fa dimenticare ogni cosa, rendendo necessario sospendere l'azione pubblica contro i delinquenti e fermare la macchina della giustizia; l'inutilità sociale di punire un reato di cui non esiste più alcuna memoria ; il peso del rimorso gravante sul reo per venti o trent'anni che costituisce anch'esso un castigo o, in assenza di rimorso, il timore continuo di essere sottoposto al giudizio, mentre una condanna a morte dopo un periodo di tempo così lungo infliggerebbe una sofferenza molto più forte di quella comminata subito dopo la commissione del reato.

Tuttavia, secondo De Foresta, una ragione ben più sostanziale giustificava la prescrizione in materia penale: la procedura penale vigente stabiliva che non ci potesse essere condanna se il reato non veniva accertato attraverso un dibattimento pubblico, ed era illusorio che si potesse formulare su di un inquisito un giudizio serio di innocenza o di colpevolezza venti o trent'anni dopo la commissione del reato; sia l'accusato sia i testimoni potevano accampare il pretesto di non ricordare più i fatti. Infine, il ministro sottolineava come la disposizione fosse la medesima anche nel Codice francese del 1810, «nel quale non vi è eccezione di sorta in fatto di prescrizione ${ }^{98}$.

\section{De Foresta e l'approvazione della cosiddetta legge sui conventi}

L'appoggio di De Foresta alle scelte politiche di Cavour fu evidente quando, il 28 novembre del 1854, la legge sui conventi, o meglio il progetto di legge intitolato Soppressione di comunità e stabilimenti religiosi ed altri provvedimenti per migliorare la condizione dei parrochi più bisognosi, fu presentata da Rattazzi, ministro della Giustizia e reggente il ministero dell'Interno, e da Cavour, che rivestiva anche la carica di ministro delle Finanze ${ }^{99}$. Si tratta della legge che sopprimeva alcuni ordini religiosi, capitoli e benefici, e dalla quale veniva creata una Cassa ecclesiastica e fissata la quota annua di concorso da pagarsi dagli altri enti morali ed ecclesiastici.

II Giurista, nella tornata del 16 febbraio 1855, si pronunciò a favore del disegno di legge, prendendo la parola il giorno dopo che il ministro di Grazia e Giustizia Rattazzi ebbe concluso il discorso di presentazione del progetto, iniziato l'11 gennaio.

\footnotetext{
${ }^{98}$ Cfr. Intervento di G. de Foresta, Tornata del 19 marzo 1857, in Atti del Parlamento Subalpino, Discussioni, (IV) 2A, 1873, pp. 1076-1077.

${ }_{99}$ Cfr. Atti del Parlamento Subalpino, Documenti, III, 1869, pp. 1631-1640.
} 
È interessante notare come il deputato nizzardo, riprendendo quanto dichiarato da Rattazzi ${ }^{100}$, esponesse le sue considerazioni circa le questioni che egli stesso, come anche altri deputati intervenuti nel dibattito, si era posto esaminando "una legge di tanta importanza»: se la Camera avesse il potere di realizzare quanto prevedeva il progetto ministeriale, se fosse legittimo farlo, se fosse il momento opportuno per agire e, soprattutto, se le disposizioni del progetto di legge fossero sufficienti per conseguire lo scopo che ci si proponeva di raggiungere ${ }^{101}$.

Nel valutare la competenza della Camera, cioè del potere politico, a decidere la sorte degli enti ecclesiastici di cui si occupava il progetto, De Foresta analizzò separatamente le tre componenti - «le corporazioni religiose, i capitoli delle collegiate ed i benefizi semplici, e la quota di concorso a carico dei benefizi» ${ }^{102}$ - sulle quali il progetto di legge intendeva intervenire. In quanto alle prime due istituzioni, parti dal principio che esse «non possono né costituirsi né esistere senza il simultaneo concorso dell'appoggio dell'autorità spirituale e dell'autorità temporale» e che, quindi, sia lo Stato che la Chiesa avevano il diritto di cancellarli se, per motivi specifici, lo ritenevano conveniente. Per quanto riguardava le proprietà delle corporazioni religiose, il deputato di Nizza ricordò che il Codice civile, da un lato, riconosceva nell'articolo 433 che anch'esse erano beni ecclesiastici e stabiliva, dall'altro, nell'articolo 419 , che questi stessi beni, quando diventavano vacanti per la soppressione delle corporazioni, appartenevano allo Stato ${ }^{103}$.

Di conseguenza De Foresta concluse che:

[...] sia che si ammetta, sia che si contesti che i beni delle corporazioni religiose soppresse si devolvano allo Stato come beni vacanti, non si potrà mai negare allo Stato il diritto almeno di raccoglierli, come rappresentante la Chiesa dello Stato medesimo e di convertirli ad usi ecclesiastici. Le stesse considerazioni valgono anche per i capitoli delle collegiate ed i benefici semplici, giacché anche questi sono informati da due distinti attributi, spirituale l'uno e temporale l'altro, e cessano pertanto di esistere quando una delle due autorità li privi del suo appoggio ${ }^{104}$.

100 Intervento di Urbano Rattazzi, Tornata dell'11 gennaio 1855, in Atti del Parlamento Subalpino, Discussioni, (VI) 3A, 1870, pp. 2630 e ss.

101 Intervento di G. de Foresta, Tornata del 16 febbraio 1855, in Atti del Parlamento Subalpino, Discussioni, (VI) 3A, 1870, p. 2840.

${ }^{102}$ Sull'argomento leggasi Soffietti, 2009, pp. 293-302, Campobello, 2015, e la voce "Quota di concorso» in Enciclopedia Italiana (1935), redatta da Jemolo.

${ }^{103}$ Art. 419: «È patrimonio dello Stato, ossia della Corona, tutto ciò che è destinato a somministrare le rendite necessarie per sostenerne i bisogni, e così i tributi, e le gabelle, i diritti sulle miniere, e sulle saline, sui beni vacanti, e sulle successioni senza eredi, od abbandonate, ed ogni altro diritto regale e demaniale.». Art. 433: "Sotto nome di beni della Chiesa s'intendono quelli che appartengono a' singoli benefizi, od altri stabilimenti Ecclesiastici.». Codice civile per gli Stati di S. M. il Re di Sardegna, 1837, pp. 114-115, 119. 104 Intervento di G. de Foresta, Tornata del 16 febbraio 1855, in Atti del Parlamento Discussioni, (VI) 3A, 1870, pp. 2840- 2841. 
In quanto poi alla terza componente, e cioè alla quota di concorso a carico degli enti ecclesiastici, il deputato nizzardo, pur riconoscendo che si trattava di una questione più grave, giungeva ad un'analoga conclusione, riutilizzando l'argomentazione delle rispettive competenze del potere spirituale e di quello temporale. Se all'autorità spirituale spettava provvedere alle cose spirituali ed a quella temporale toccava occuparsi di tutto ciò che attiene alle cose temporali - e ciò ovviamente valeva sia nei confronti degli ecclesiastici che dei laici - il diritto di regolare l'uso di cose temporali, come i beni e i redditi degli ecclesiastici, competeva all'autorità temporale, cioè allo Stato, che li doveva ripartire «pel maggior bene della religione e della Chiesa»:

All'autorità spirituale spetta di provvedere in tutto ciò che riflette lo spirituale; all'autorità temporale appartiene di provvedere tutto quanto concerne le cose temporali, sia che riflettano gli ecclesiastici o che concernano i secolari. Difatti, che diremmo noi, o signori, se vi fosse un principe cattolico che volesse prescrivere i riti religiosi, dettare le preghiere, dicendo che egli non si immischia degli ecclesiastici, e ordina soltanto ai secolari? Noi diremmo per lo meno che egli abusa del suo potere, che invade l'autorità spirituale, che è pure sovrana ed indipendente. Per reciprocità e per conseguenza dello stesso principio non possiamo a meno di riconoscere che all'autorità spirituale non spetta di provvedere nelle cose temporali, benché riflettano gli ecclesiastici. Ora i beni, i redditi di essi sono essi o no cose temporali? Indubitatamente sono cose temporali. Quindi il diritto di regolarne l'uso, di ripartirli pel maggior bene della religione e della Chiesa spetta indubitatamente all'autorità temporale, ossia allo Stato ${ }^{105}$.

Non c'erano dubbi, a suo avviso, sull'equità del progetto, che si proponeva due fini, l'uno politico e l'altro finanziario. Quanto al primo, e cioè «sopprimere corporazioni religiose che non sono più confacenti ai bisogni dei tempi attuali», De Foresta affermò che non era necessario abolirle del tutto, ma che la personalità giuridica avrebbe dovuto essere loro accordata a due condizioni: che l'ente morale non prevedesse voti perpetui e che le corporazioni fossero dipendenti dai vescovi delle diocesi e non da autorità residenti al di fuori dello Stato. Sull'argomento De Foresta si espresse con toni meno prudenti di quelli solitamente usati:

La prima, che non fossero permessi i voti perpetui e che la legge non riconoscesse come corpi morali che quelli i cui voti fossero temporari. Quanti dolori, quante disperazioni, quanti decessi, tutt'altro che santi, non avvengono quotidianamente nei chiostri! lo non vorrei che il Governo riconoscesse corporazioni nelle quali possano temersi questi tristi risultati di una meno fervida e meno costante vocazione. La seconda, che non vi fossero corporazioni religiose indipendenti dai vescovi delle diocesi e dipendenti da un superiore che risiede fuori dello Stato. In una parola, io non vorrei che la Corte di Roma possa tenere guarnigione in qualunque città dello Stato. (Bravo!) ${ }^{106}$

\footnotetext{
${ }^{105}$ Atti del Parlamento Discussioni, (VI) 3A, 1870, p. 2842.

${ }^{106}$ Atti del Parlamento Discussioni, (VI) 3A, 1870, p. 2842.
} 
In merito al secondo obiettivo, quello finanziario, era innegabile che si trattava di un fine giusto, poiché la legge in questione intendeva «impiegare i redditi provenienti dai beni di queste corporazioni per sovvenire ai parroci bisognosi, a quelli stessi ai quali il Parlamento ha nel bilancio di quest'anno depennati tutti i sussidi» ${ }^{107}$.

Per quanto concerne poi l'opportunità della legge, De Foresta ne era convinto sia perché era consapevole che l'opinione pubblica «reclamava altamente un provvedimento a questo riguardo", sia perché la legge era conveniente per il Governo che in quel momento disponeva di una forte maggioranza. Lo era per i contribuenti, ai quali non si potevano imporre ulteriori aggravi fiscali per il sostentamento dei parroci bisognosi, ed anche per le istituzioni stesse, che non sarebbero state certamente sfrattate dai loro conventi.

Infine, il giudizio sul progetto ministeriale nel suo complesso era positivo, anche se De Foresta si riservava di proporre alcuni emendamenti volti a migliorarlo, come la soppressione dei «diritti di stola» ${ }^{108}$. In proposito egli spiegò che, se questi diritti erano percepiti come compenso per la somministrazione dei sacramenti, ciò era sconveniente e vietato dalle stesse leggi canoniche, costituendo una specie di simonia; se invece erano riscossi come una sorta di imposta per provvedere alle spese connesse al culto e per integrare le congrue dei parroci, costituivano una violazione dello Statuto ${ }^{109}$, poiché qualsiasi tipo di imposta doveva essere votata dal Parlamento ${ }^{110}$.

Nel corso del dibattito parlamentare dei giorni successivi, De Foresta intervenne nuovamente.

Una prima volta, il 22 febbraio 1855, chiese spiegazioni in merito al mantenimento dell'orfanotrofio femminile delle Cesoline ${ }^{111}$ di Nizza, così come anche il deputato Lorenzo Pareto circa analoghi istituti genovesi, dediti all'educazione di ragazze povere ed orfane, ricevendo conferma dal ministro Rattazzi che questi istituti non erano considerati da sopprimere, in quanto non appartenenti ad alcun ordine religioso "laicale o monastico»" ${ }^{112}$. Una seconda volta, il 28 febbraio 1855 , tornò nuovamente sull'argomento dei diritti di stola proponendo di aggiungere al paragrafo 4 dell'articolo 6 del disegno di legge un emendamento contenente la soppressione di questi diritti e il pagamento di una «pensione di giubi-

\footnotetext{
${ }^{107}$ Atti del Parlamento Discussioni, (VI) 3A, 1870, p. 2842.

${ }^{108}$ Ricci, De Luca, Bertola, 1936.

${ }^{109}$ Art. 10 «La proposizione delle leggi apparterrà al Re ed a ciascuna delle due Camere. Però ogni legge d'imposizione di tributi, o di approvazione dei bilanci e dei conti dello Stato, sarà presentata prima alla Camera dei Deputati. » Raccolta degli Atti del Governo di S. M. il Re di Sardegna, vol. XVI, Dal $1^{\circ}$ gennaio a tutto dicembre 1848, s.d., p. 36.

110 Intervento di G. de Foresta, Tornata del 16 febbraio 1855, in Atti del Parlamento Discussioni, (VI) 3A, 1870, pp. 2843-2844.

${ }^{111}$ Sappia, 1903, pp. 55-58 e 73-80; Vernier, 1993, pp.168-171.

112 Interventi di L. Pareto, U. Rattazzi e G. de Foresta, Tornata del 22 febbraio 1855, in Atti del Parlamento Subalpino, Discussioni, (VI) 3A, 1870, pp. 2934-2935.
} 
lazione ai parroci ${ }^{113}$. Tuttavia, in seguito, accondiscese all'invito di Cavour a non insistere sulla soppressione di quei diritti ed a ritirare la parte della sua proposta che li riguardava. Cavour dichiarò, infatti, che quella dei diritti di stola, oltre ad essere «una questione gravissima e complicatissima» che il Governo non avrebbe avuto i mezzi per affrontare, era «questione di disciplina ecclesiastica, alla quale il Governo deve rimanere assolutamente estraneo»"114.

Il 2 marzo il deputato nizzardo votò a favore dell'ultimo articolo del disegno (art. 23 «I ministri degli affari ecclesiastici e delle finanze renderanno annualmente conto al Parlamento della cassa stabilita all'articolo 6, e dei beni destinati ad uso di servizio pubblico.») e quindi dell'intero progetto ${ }^{115}$.

Il discorso pronunciato da De Foresta, che fin dalle prime parole si era dichiarato convinto della positività del progetto, era dunque pienamente in linea con le esigenze del Governo.

In quel momento il primo governo Cavour, formatosi il 4 novembre 1852 attraverso un accordo con la sinistra nel cosiddetto 'connubio', disponeva, come aveva sottolineato lo stesso deputato nizzardo, di una forte maggioranza in Parlamento ${ }^{116}$.

Ciò nonostante la crisi finanziaria del Paese era grave: il deficit del bilancio statale costringeva all'aumento della pressione fiscale e imponeva economie. L'opposizione si stava rafforzando, mobilitando i cattolici contrari all'anticlericalismo del Governo, gli ambienti vicini alla Corte, il clero e l'apparato burocratico.

Ad un criterio di economia, ma anche ad un preciso disegno tendente a ridimensionare l'influenza della Chiesa, era dunque ispirato il progetto di legge sullo scioglimento degli ordini religiosi contemplativi, cioè di quelli che non erano dediti all'istruzione, alla predicazione o all'assistenza.

La discussione del progetto riprese il 5 maggio 1855 al Senato e, solo il 9 maggio, il giurista Luigi Des Ambrois de Nevâche e il patriota Giacinto Provana di Collegno riuscirono a trovare un accordo tra Governo e Senato: i religiosi presenti nei conventi degli enti soppressi non sarebbero stati cacciati, ma sarebbero

${ }^{113}$ L'emendamento proposto da De Foresta era il seguente: «Nel pagamento di una pensione di giubilazione ai parroci, che col consenso del vescovo e del Governo rinuncieranno al beneficio parrocchiale, ed a quelli che per infermità o vecchiaia diverranno inabili ad adempiere al loro ufficio, come sarà regolato per legge ulteriore; Nella soppressione, mediante, occorrendo, equo e proporzionato compenso, della percezione di qualunque diritto di stola od altro obbligatorio in favore dei parroci, come sarà pure regolato per legge ulteriore». Prima Tornata pomeridiana del 28 febbraio 1855, in Atti del Parlamento Subalpino, Discussioni, (VI) 3A, 1870, pp. 3052-3053.

114 Intervento di Camillo Benso, conte di Cavour, Prima Tornata pomeridiana del 28 febbraio 1855, in Atti del Parlamento Subalpino, (VI) 3A, 1870, p. 3053.

${ }_{115}$ Tornata del 2 marzo 1855, in Atti del Parlamento Subalpino, Discussioni, (VI) 3A, 1870, pp. 3115-3116

116 Intervento di De Foresta, Tornata del 16 febbraio 1855, in Atti del Parlamento Subalpino, Discussioni, (VI) 3A, 1870, p. 2843. 
rimasti fino alla naturale estinzione delle loro comunità. Approvata dal Senato il 22 maggio, la legge fu ridiscussa e approvata dalla Camera il 28 maggio 1855 con 95 voti favorevoli e 23 contrari su 118 deputati votanti ${ }^{117}$ e firmata dal Re il 29 maggio $^{118}$.

\section{La legge sulla repressione dei reati di apologia dell'assassinio politico e di cospirazione contro la vita dei capi di stato esteri}

De Foresta tornò in primo piano nel febbraio 1858 quando, per soddisfare la Francia dopo l'attentato di Orsini contro Napoleone IIII19, fu necessario introdurre una legge sulle sanzioni da infliggere ai cospiratori contro i capi di stato stranieri, sull'apologia dell'assassinio politico a mezzo stampa e sulla riforma del giurì ${ }^{120}$.

Il progetto di De Foresta, approntato due anni prima, prevedeva fino a dieci anni di lavoro forzato per i cospiratori contro la vita di sovrani stranieri quando vi fossero stati atti preparatori, fino a un anno di carcere per l'apologia dei crimini politici attraverso i giornali e, infine, un controllo minuzioso da parte dell'esecutivo sulla formazione delle giurie dei tribunali penali.

Ho l'onore di presentare alla Camera un progetto di legge per cui si punisce la cospirazione contro la vita dei sovrani e dei capi dei Governi stranieri, si stabilisce il minimo della pena e si dà la legale definizione del reato di apologia dell'assassinio politico, e si attribuisce al sindaco ed a due consiglieri comunali la formazione della lista semestrale dei giudici del fatto pei reati di stampa ${ }^{121}$.

La discussione parlamentare spettò quasi esclusivamente a Cavour che riuscì a convincere l'opposizione dell'opportunità di una legge, imposta dall'alleato più potente, ma che, secondo l'opposizione, costituiva una palese violazione delle prerogative del sovrano del Regno Sardo: il ministro della Giustizia intervenne su questo punto il 17 e 19 aprile 1858, al fine di dimostrare che tale prevaricazione non esisteva, almeno, sul piano giuridico.

La discussione generale del progetto per «disposizioni contro i reati di cospirazione contro i sovrani stranieri, l'apologia dell'assassinio politico, e per la composizione della lista dei giurati» iniziò alla Camera il 13 aprile 1858 con gli interventi

117 Tornata del 28 maggio 1855, in Atti del Parlamento Subalpino, Discussioni, (VII) $4^{\circ}$, 1870, p. 3711.

118 Legge del 29 maggio $1855 n^{\circ} 878$, con la quale vengono soppressi alcuni ordini religiosi, capitoli e benefizi, viene creata una Cassa ecclesiastica e fissata la quota annua di concorso da pagarsi dagli altri enti morali ecclesiastici. Raccolta degli Atti del Governo di Sua Maestà il Re di Sardegna, volume XXIV, s.d., pp. 741-752.

${ }^{119}$ Circa i riflessi politico-giuridici dell'attentato Orsini, leggasi Sardo, IV, 1966, pp.234-254. ${ }^{120}$ Sugli omicidi politici può essere utile anche la lettura di Ford, 1990, 546 p.; vedasi anche Louessard, 2000, $401 \mathrm{p}$.

${ }^{121}$ Cfr. Tornata del 17 febbraio 1858, in Atti del Parlamento Subalpino, Discussioni, (III) 1 A, 1874, p. 600. 
dei deputati Solaro della Margarita e Pareto contrari al progetto e quelli favorevoli dei deputati Boggio, Mamiani e Farini. II dibattito proseguì fino al 29 aprile, quando il progetto fu approvato con 110 favorevoli e 42 contrari. In Senato il disegno di legge fu presentato da De Foresta il 3 maggio e, dopo la relazione dell'ufficio centrale (17 maggio, relatore Sclopis), fu discusso dall' $1{ }^{\circ}$ al 4 giugno, quando passò con 50 voti favorevoli e 5 contrari. La legge fu promulgata il 20 giugno 1958.

Alla Camera il dibattito continuò dunque per quindici giorni, ma, già il giorno successivo alla presentazione del progetto, il deputato Lorenzo Valerio aveva rivolto la seguente domanda al primo ministro Cavour, nonché ministro dell'Interno e degli Affari esteri:

Dopo l'attentato del 14 gennaio, la stampa, più specialmente la stampa estera, perchè quella del paese fu molto riservata su questa materia, ebbe a ripetere più volte che alcune note per parte del Governo imperiale francese sono state rivolte al Governo sardo. Io chiedo se questo fatto sia vero, e se è vero, domando se il presidente del Consiglio dei ministri avrebbe qualche grave difficoltà a deporre sul banco della Presidenza la nota che gli fosse stata in proposito trasmessa dal Governo francese ${ }^{122}$.

Cavour aveva risposto che dal Governo francese erano state indirizzate note redatte all'incirca nei medesimi termini all'Inghilterra, al Belgio, alla Svizzera ed al Piemonte, e si era detto disposto a comunicare quella ricevuta dal Governo e a discutere l'opportunità di renderla pubblica attraverso la stampa, se "all'occasione del bilancio degli affari esteri, od in altra circostanza, una Commissione della Camera crederà di dover chiedere comunicazione di questa nota». Lorenzo Valerio, in quella circostanza, si era dichiarato soddisfatto della risposta, ma aveva sottolineato di non comprendere né le ragioni di contestare l'opportunità della sua domanda né quelle per cui il presidente del Consiglio intendeva lasciare alla Camera il compito di valutarla. Oltre a ciò aveva affermato di considerare utile "far conoscere documenti diplomatici di questa natura» e «vantaggioso che il paese conosca in quali condizioni egli si trova per sapersi condurre con quella prudenza e con quella fermezza che sono necessarie a tutelare il proprio onore ${ }^{123}$.

Nel corso del dibattito parlamentare, l'opposizione di alcuni deputati - tra i quali Brofferio, Casalis, Sineo - al progetto di legge di De Foresta fu piuttosto decisa.

L'avvocato Angelo Brofferio, esponente della sinistra, oltre ad avanzare obiezioni legali al progetto di legge, lo giudicò severamente dal punto di vista della politica internazionale, dichiarando:

122 Intervento di L. Valerio, Tornata del 18 febbraio 1858, in Atti del Parlamento Subalpino, Discussioni, (III) 1 A, p. 603.

${ }^{123}$ Interventi di Camillo Benso, conte di Cavour e di L. Valerio, in Atti del Parlamento Subalpino, Discussioni, (III) 1 A, p. 603. 
Che questa infausta legge sia un regalo straniero, io credo che nessuno possa metterlo in dubbio. Si potrà forse o sulla forma o sul concetto più o meno esplicito delle parole disputare; ma che questa legge non ci venga da straniera benevolenza, torno a ripeterlo, non è possibile che niegare si possa. In qual tempo ci fu presentata questa legge? Dopo il 14 gennaio, mentre una egual legge era presentata nell'Inghilterra e nel Belgio, e pressanti sollecitazioni si facevano alla Svizzera. I casi, i tempi, le circostanze, e, se non basta, le parole stesse del Ministero consegnate nel preambolo della legge ci dichiarano apertamente che noi ci accingiamo a tanto per compiere ad un dovere internazionale. Non è adunque con animo spontaneo e volenteroso che entriamo in questo arringo ${ }^{124}$.

Riccardo Sineo, uno dei più tenaci avversari della politica di Cavour, il 19 aprile così concludeva il suo intervento alla Camera:

Riassumendo i miei pensieri, io conchiudo col ripetere che nessuna necessità ci spinge a discutere attualmente le gravi materie sulle quali è chiamata l'attenzione vostra; che questa legge fu dettata in parte da un misero puntiglio contro i giurati, i quali fecero nobilmente il loro dovere; fu dettata, sotto altro aspetto, da un indecoroso, eccessivo, inopportuno ossequio, e voi non vorrete che concediamo ciò che nessuno ci chiede. D'altra parte le proposte fatte dal Ministero e da coloro che col Ministero stanno sono di tale natura che, introdotte nella legislazione, tendono a sovvertirne i principii. Ripudiate dunque per ora queste proposte e pensate, o signori, di quanti gravi argomenti la nazione vi chiederà conto; pensate a ciò che avete fatto in questi cinque mesi per avanzare l'edifizio di quelle riforme che il popolo da molti anni domanda d'urgenza, e che le passate Legislature lasciarono intentate ${ }^{125}$.

De Foresta prese la parola nella medesima seduta per difendere il progetto, e s'impegnò innanzi tutto a contestare un'affermazione contenuta, a suo avviso, nella relazione della Commissione di cui Valerio era il relatore ${ }^{126}$, riguardante l'art. $1^{127}$, e cioè che punire la cospirazione contro la vita dei sovrani e dei capi

124 Intervento di A. Brofferio, Tornata del 14 aprile 1858, in Atti del Parlamento Subalpino, Discussioni, (IV) 2 A, 1874, p. 1202.

125 Intervento di Sineo, Tornata del 19 aprile 1858, in Atti del Parlamento Subalpino, Discussioni, (IV) 2 A, 1874, p. 1275.

${ }^{126}$ La Commissione della Camera incaricata di esaminare il progetto intitolato «Penalità per la cospirazione contro la vita dei Sovrani e Capi dei Governi esteri. Definizione e repressione del reato di apologia dell'assassinio politico. Riforma dei Giurati» era costituita dai deputati Gastaldetti, Brofferio, Cotta-Ramusino, Miglietti, Farina, Buffa e Valerio, che ne era il relatore. Nella tornata del 23 marzo 1858, Valerio consegnò al banco della Presidenza la relazione da essa compilata sul progetto di legge. Atti del Parlamento Subalpino, Documenti, I, 1873, p. 648ss.

${ }^{127}$ Progetto di legge presentato alla Camera il 17 febbraio 1858, dal ministro di Grazia e Giustizia (De Foresta): art. 1: "La cospirazione contro i Sovrani e i Capi dei Governi stranieri è punita colla reclusione estensibile a 10 anni di lavori forzati quando vi sieno atti preparatori, salve le maggiori pene stabilite dal Codice penale quando sianvi stati atti di 
dei Governi esteri contrastava con i principi del diritto penale. La relazione della Commissione affermava, tra l'altro, che

[...] se si comincia a introdurre il sistema di tutelare col nostro Codice penale i diritti e gl'interessi dei principi e capi di Governo stranieri con provvedimenti eccezionali suggeriti dalla ragione politica, potrà domandarsi per qual causa una simile tutela e protezione debbasi limitare soltanto a garantire la loro vita, e non già tanti altri loro diritti più o meno fondati, dai pericoli di disegni e concerti che si ordissero sul nostro territorio; e sarebbe d'uopo in tal caso moltiplicare a dismisura le nuove sanzioni da introdursi nel nostro Codice penale ${ }^{128}$.

Egli muoveva dall'assunto, riconosciuto ormai da tutti i criminalisti, tra i quali citava Cesare Beccaria e Pellegrino Rossi, che la società ha il diritto di punire quando ritiene che ciò sia nell'interesse generale dei suoi membri, cioè dal momento in cui «il proposito di delinquere» viene manifestato perché in quel momento sussistono sia il dolo sia il danno sociale ${ }^{129}$.

De Foresta precisò, poi, che generalmente si puniscono il complotto e gli atti preparatori soltanto nei reati contro lo Stato e in quelli contro la persona del proprio sovrano e la sua famiglia, non perché la società non abbia il diritto di farlo in tutti i casi, ma perché nei reati comuni è difficile che il misfatto sia preceduto da una cospirazione e da atti preparatori. In più, oltre ad essere problematico dimostrare l'esistenza del nesso necessario tra l'atto preparatorio e la consumazione del delitto, è possibile che chi ha inteso commettere un reato vi rinunzi. Infine, provare il sussistere della semplice intenzione di commettere un crimine per punirlo comporterebbe vessazioni della libertà dei cittadini, e perciò la legge si limita a misure preventive, quali la proibizione della vendita di sostanze velenose o del porto di armi 'insidiose'. Il suo ragionamento si concludeva con queste parole:

Insomma la società pone nella bilancia, da una parte, la difficoltà della prova e gli inconvenienti che potrebbero risultare dalla punizione degli atti preparatorii, dall'altra, il vantaggio che dall'impedirli, per quanto possibile, derivare ne possono e quasi sempre o meglio sempre limitasi a mezzi preventivi, quali sono la proibizione di vendere sostanze velenose, di portare armi insidiose e simili ${ }^{130}$.

A differenza di quanto sostenuto dal relatore della Commissione, secondo il quale prima di allora non era mai stato proposto da nessuno di «punire la cospirazione e gli atti preparatorii del reato, tranne nei casi di sicurezza interna ed

esecuzione che costituiscano un tentativo a termini del capo III, titolo II, libro $1^{\circ}$ di detto Codice, o sia il crimine stato consumato.» Atti del Parlamento Subalpino, Documenti, I, 1873, pp. 646-648.

${ }^{128}$ Atti del Parlamento Subalpino, Documenti, I, 1873, p. 648.

129 Intervento di De Foresta, Tornata del 19 aprile 1858, in Atti del Parlamento Subalpino, Discussioni, (IV) 2 A, 1874, pp. 1275-1276.

${ }^{130}$ Atti del Parlamento Subalpino, Discussioni, (IV) 2 A, 1874, p. 1277. 
esterna dello Stato e di pericolo contro la vita del proprio sovrano ${ }^{131}$, la previsione di reato contemplata all'art. $1^{\circ}$ del progetto in discussione esisteva da tempo in alcuni codici. Per comprovare le sue considerazioni, De Foresta si riferì agli articoli 41 e 42 del Codice penale di Federico di Prussia, promulgato nel 1794, ed a quello del 1851, nonché ai codici di altri stati tedeschi, in cui la disposizione oggetto del dibattito era prevista, benché fosse stata aggiunta, in quello del 1851, la condizione della "reciprocità» e questa fosse stata limitata, negli altri, ai prìncipi alleati e membri della Confederazione. Ricordò poi che nel Regno di Sardegna la semplice cospirazione contro il proprio sovrano, anche se non preceduta da «atti preparatori» era punita con la morte, mentre il progetto di legge in discussione proponeva pene meno gravi:

Noi domandiamo solamente che il complotto per commettere l'assassinio sia punito colla reclusione, se vi ha semplice cospirazione, coi lavori forzati a tempo, se già sianvi atti preparatorii, e la minoranza della Commissione mitigava ancora queste proposte, limitando la pena della reclusione ai casi in cui la cospirazione sia già susseguita da atti preparatoriii ${ }^{132}$.

Ciò allo scopo di evitare che nel paese si violassero $\mathrm{i}$ «principii eterni della morale» e si preparassero i mezzi per compiere un assassinio in un qualsiasi Stato estero.

In secondo luogo, il ministro dichiarò che non era possibile considerare, come faceva la Commissione parlamentare, che i reati politici fossero già contemplati all'art. 179 del Codice penale vigente, perché in esso si faceva riferimento unicamente ad "atti ostili»" ${ }^{133}$, cioè ad atti che «quantunque non siano reati, pure il Governo non volle che potessero essere messi in opera dai privati per le conseguenze che avere potevano all'estero, quando egli, che doveva conoscerne l'importanza, non li avesse approvati» ${ }^{134}$.

In quanto poi all'illegittimità di modificare il Codice penale con l'aggiunta di questa nuova disposizione, De Foresta ribadì che qui si trattava di punire un atto "profondamente immorale che è reato in se stesso", colmando così una lacuna del Codice penale, e non di fare concessioni a pressioni esterne. Infatti, quella in discussione:

\footnotetext{
${ }^{131}$ Atti del Parlamento Subalpino, Discussioni, (IV) 2 A, 1874, p. 1278.

${ }^{132}$ Atti del Parlamento Subalpino, Discussioni, (IV) 2 A, 1874, p. 1279.

133 Libro II, Titolo II Dei reati di lesa maestà, Capo I Dei reati contro la sicurezza esterna dello Stato, Art. 179: «Chiunque avrà con atti ostili non approvati dal Governo esposto lo Stato ad una dichiarazione di guerra, sarà punito colla reclusione o colla relegazione, secondo le circostanze: se la guerra ne fosse seguita, la pena sarà dei lavori forzati a tempo.» Codice penale per gli Stati di S.M. il Re di Sardegna, op. cit., pp. 52-53.

${ }_{134}$ Intervento di G. De Foresta, Tornata del 19 aprile 1858, in Atti del Parlamento Subalpino, Discussioni, (IV) 2 A, 1874, p. 1279.
} 
[...] non è legge fatta in seguito all'attentato del 14 gennaio, ma era già ben da prima lungamente meditata; è una legge interamente stralciata da un generale progetto di riforma del Codice penale. In conseguenza non è questa una disposizione di circostanza ed unicamente voluta dalle relazioni internazionali, ma è disposizione che deve completare il Codice penale, perché provveda sufficientemente alla moralità del paese ${ }^{135}$.

Un'ultima considerazione fu riservata all'obiezione di chi sottolineava come fosse illegale punire le cospirazioni e gli atti preparatori contro la vita di sovrani di paesi stranieri, in altri casi oltre a quelli previsti nel Codice penale del Regno di Sardegna, dal momento che in esso la cospirazione non era adeguatamente definita. Pur riconoscendo la veridicità di questa affermazione e la necessità di distinguere il semplice complotto dagli atti preparatori e questi da quelli di esecuzione, il progetto di legge proposto rimediava all'inconveniente, comminando una pena specifica per la semplice cospirazione ed un'altra più grave quando essa fosse preceduta da atti preparatori. Ad avviso del ministro, insignificante era anche un'altra obiezione: che con l'adozione della modifica prevista dall'art. 1 del progetto in discussione si andasse incontro ad una situazione assurda, qualora una cospirazione, ordita in vari paesi dotati di leggi diverse, fosse scoperta e punita in alcuni, mentre in altri non lo fosse. Infatti, oltre ad essere «un principio costante che tutti i reati debbono essere giudicati secondo le leggi dei paesi in cui quelli sono commessi», un paese è tanto più "onorato» e le sue leggi sono tanto più "pregevoli», quanto più in esso si tutela la morale pubblica ${ }^{136}$.

In quanto all'art. 2 del progetto di legge ${ }^{137}$ - che introduceva il reato di apologia dell'assassinio politico a mezzo stampa, considerandolo tale se compiuto sia approvando l'assassinio politico sia scusandolo o giustificandolo, e puniva anche l'apologia indiretta, cioè quella di chi si fosse limitato a riprodurre scritti, stampati o opere altrui - esso altro non era che la logica conseguenza del primo:

Dacché noi abbiamo proposto una disposizione per impedire che propaghisi ed attecchisca la scellerata teoria dell'assassinio politico e del regicidio, e si traduca nei fatti, saremmo stati improvvidi ed illogici ove non avessimo cercato impedire che la medesima si diffonda cogli scritti e colla stampa. Credo che non potrò meglio riferire il pensiero che ebbe il Ministero proponendovi quest'articolo, che col

\footnotetext{
${ }^{135}$ Atti del Parlamento Subalpino, Discussioni, (IV) 2 A, 1874, p. 1279.

${ }^{136}$ Atti del Parlamento Subalpino, Discussioni, (IV) 2 A, 1874, p. 1280.

137 Progetto di legge presentato alla Camera il 17 febbraio 1858, dal ministro di Grazia e Giustizia (De Foresta): art. 2: "L'apologia dell'assassinio politico, ovunque commesso, è punito colla pena del carcere da tre mesi a un anno, oltre ad una multa estensibile a lire mille. Tale reato si commette ogni qual volta con alcuno dei mezzi indicati nell'art. $1^{\circ}$ della legge 26 marzo 1848 si approva l'assassinio politico, ovvero si cerca di giustificarlo o di scusarlo. Vi sarà luogo all'applicazione della pena sovrastabilita anche nel caso in cui I'apologia sia stata fatta indirettamente o colla riproduzione di scritti, di stampati o opere altrui.» Atti del Parlamento Subalpino, Documenti, I, 1873, pp. 646-648.
} 
ripetere le parole dette dal signor Salvandy, relatore della Commissione, il quale riferiva sulla legge del 9 settembre 1835: "Nous voulons (diceva egli), qu'il soit établi que ce qui est fixé par la loi comme un crime en action soit aussi crime en discours, que le panégirique de ce qui est condamné par la législation publique soit flétri par l'opinion universelle.» Ecco qual fu il pensiero per cui, dopo avere noi proposto una pena contro la cospirazione e gli atti preparatorii dell'assassinio politico, abbiamo pensato essere dover nostro d'impedire che questo crimine a cui ponevamo argine, venisse giornalmente lodato, e vi si desse un incentivo per mezzo della stampa ${ }^{138}$.

De Foresta spiegò la genesi di questo articolo, riferendosi alle leggi francesi del 17 maggio $1819^{139}$ e del 9 settembre $1835^{140}$ :

L'articolo 8 della legge 17 maggio 1819 puniva gli oltraggi alla moralità pubblica, alla religione e ai buoni costumi, colla pena del carcere da un mese ad un anno e con una multa di lire 200 . Venute dopo il 1830 le prime offese contro l'autorità regia e contro la proprietà per i progressi del socialismo, ed avveratisi alcuni tentativi di regicidio, si credette insufficiente una tale disposizione, e colla legge 9 settembre 1835, all'articolo 8, si stabilì che sarebbero puniti anche 'toute attaque contre la propriété, le serment, le respect dù aux lois, toute apologie des faits prévus par la loi pénale, provocation à la haine contre les diverses classes de la société," [...] ecc..., con facoltà ai tribunali di applicare anche il doppio della pena, secondo le circostanze ${ }^{141}$.

Quando era stata approvata la legge sulla stampa del 26 marzo 1848, i due suddetti articoli furono recepiti dagli artt. 17 e $24^{142}$, ma, nonostante quest'ultimo punisse «ogni apologia di fatti qualificati crimini o delitti dalla legge penale», la legge non definiva il crimine di «apologia» né fissava il minimum della pena. Il che lasciava ai magistrati un ampio margine di discrezionalità nel deciderla, poiché l'art. 17 fissava una pena non superiore ad un anno di carcere o pene di polizia

${ }^{138}$ Intervento di De Foresta, Tornata del 19 aprile 1858, in Atti del Parlamento Subalpino, Discussioni, (IV) 2 A, 1874, p. 1280.

${ }^{139}$ Loi sur la répression des crimes et des délits commis par la voie de la Presse ou par tout autre moyen de publication, 17 mai 1819, art. 8 «Tout outrage à la morale publique et religieuse, ou aux bonnes mœurs, par l'un des moyens énoncés en l'article 1er, sera puni d'un emprisonnement d'un moi à un an, et d'une amende de seize francs à cinq cents franc.» : Bulletin des lois du Royaume de France, VIle Série, Tome VIII, 1819, B. $\mathrm{n}^{\circ}$ 278, p. 467.

${ }^{140}$ Loi du 9 septembre 1835, sur les crimes, délits et contraventions de la Presse et des autres moyens de publication, in Bulletin des lois du Royaume de France, IXe Série, Ire Partie, Tome VII, 1835, B. n 155, p. 249.

141 Intervento di De Foresta, Tornata del 19 aprile 1858, in Atti del Parlamento Subalpino, Discussioni, (IV) 2 A, 1874, p. 1281.

142 Regio editto sulla libertà della stampa, 26 marzo 1848, N. ${ }^{\circ}$ 695: Artt. 17 e 24, in Raccolta degli Atti del Governo di S. M. il Re di Sardegna, vol. XVI, Dal $1^{\circ}$ gennaio a tutto dicembre 1848, s.d., pp. 239 e 241. 
in base alle circostanze, e quindi, in teoria, la pena effettivamente comminata era molto lieve. Proprio tale elemento induceva De Foresta, che pur si dichiarava fiducioso che i magistrati attribuissero una pena proporzionata alla gravità del reato, ad una riflessione sulla pericolosità di lasciare loro il compito di supplire alle carenze delle leggi:

[...] o signori, vi prego di considerare che non vi ha cosa più pericolosa per un paese di quella di dover sperare che le sentenze dei magistrati correggano il difetto della legge. lo lo ripeto, sono convinto che i magistrati non darebbero mai luogo a questo sconcio di vedere condannato ad un giorno d'arresto e a due lire di multa colui che avesse fatta l'apologia del regicidio, del parricidio, del più grave reato; ma, dico, guai a quel paese che deve calcolare sull'arbitrio dei magistrati per correggere un difetto della legge! ${ }^{143}$

Per prevenire qualsiasi dubbio interpretativo ${ }^{144}$ dell'art. 24 della suddetta legge sulla stampa in cui si parlava di «apologia di fatti qualificati crimini o delitti dalla legge penale», era perciò parso indispensabile che una definizione del reato di apologia dell'assassinio politico fosse inserita nella nuova legge, e che in essa si prevedesse anche la cosiddetta "apologia indiretta», cioè quella fatta indirettamente riproducendo scritti altrui.

Tuttavia l'art. 2 della legge 20 giugno 1858 risultò poi così formulato: "L'apologia dell'assassinio politico per mezzo della stampa, o di alcun altro dei mezzi indicati nell'art. $1^{\circ}$ della legge 26 marzo 1848, è punita a termini dell'art. 24 della stessa legge, escluse sempre le pene di polizia, sia che venga l'assassinio espressamente approvato, sia che si cerchi soltanto di giustificarlo» ${ }^{145}$. Fu così lasciata al giudice un'ampia discrezionalità nel graduare la durata del carcere e furono escluse le sole pene di polizia, mentre il testo approvato non comprese più la cosiddetta 'apologia indiretta', che aveva suscitato polemiche anche in seguito al processo intentato al periodico la Ragione ${ }^{146}$ per l'apologia dell'attentato perpetrato da Felice Orsini.

${ }^{143}$ Intervento di De Foresta, Tornata del 19 aprile 1858, in Atti del Parlamento Subalpino, Discussioni, (IV) 2 A, 1874, p. 1281.

144 De Foresta si riferisce al processo intentato contro il periodico di Oneglia, I/ Pensiero, per apologia dell'attentato del 14 gennaio. In questo caso il direttore e il gerente del giornale contestarono l'accusa loro rivolta, perché «essendo il giornale accusato di avere fatto l'apologia d'un fatto avvenuto all'estero, che non poteva essere punito dal Codice penale, non era applicabile al caso concreto l'art. 24 della legge sulla stampa.» Atti del Parlamento Subalpino, Discussioni, (IV) 2 A, 1874, p. 1282.

${ }^{145}$ Legge concernente la cospirazione contro la vita dei Sovrani stranieri, I'apologia dell'assassinio politico, e la riforma dei Giurati, 20 giugno 1858, $\mathrm{n}^{\circ}$ 2876. Raccolta degli Atti del Governo di S. M. il Re di Sardegna, vol. XXVII, Anno 1858, s.d., pp. 217-218.

${ }^{146}$ La Ragione, un settimanale di "filosofia religiosa, politica e sociale" che suscitò la simpatia dei dissidenti repubblicani di Mazzini, fu fondata a Torino nel 1854 dal filosofo Ausonio Franchi (pseudonimo di Cristoforo Bonavino): Della Volpe, 1932. 
Infine De Foresta affrontò il tema della composizione della giuria. I giurati, per i criteri in base ai quali erano scelti, risultavano inadeguati a svolgere il loro compito: la modalità del sorteggio si era rivelata insufficiente. Rimanevano, perciò, l'individuazione dei giurati per categorie o per il tramite di un'autorità pubblica, ovvero da magistrati o da altri agenti del Governo o da Commissioni. Sulla questione il ministro si dichiarò disponibile ad accettare un progetto avanzato dalla Commissione che, secondo i proponenti, garantisse maggiormente la scelta di giurati indipendenti ed imparziali.

$\mathrm{E}$, infatti, su questo punto la legge approvata il 20 giugno 1858 stabilì che, sino al 31 dicembre 1862, le liste, dalle quali dovevano essere estratti, semestralmente, i giurati chiamati a giudicare i reati commessi a mezzo stampa, sarebbero state formate da una commissione composta dal sindaco del comune sede del Magistrato d'Appello, da due consiglieri comunali e due provinciali eletti dai rispettivi corpi. In questo modo, cioè affidando provvisoriamente la compilazione delle liste a persone designate dai consessi rappresentativi degli enti locali, fu trovato un accordo con la sinistra che temeva l'ingerenza governativa nella composizione delle liste ${ }^{147}$.

\section{Conclusione}

La personalità e la carriera politica di Giovanni de Foresta sono riassumibili in una formula semplice: un liberale moderato con aperture progressiste.

Ma questa definizione è sicuramente incompleta, perché l'avvocato nizzardo era soprattutto un giurista preparato e competente, dotato di eccellenti conoscenze teoriche e tecniche, un uomo a cui non mancavano perseveranza e capacità di mediazione, fermo nel suo appoggio alla politica del conte di Cavour; abile nell'inserirsi rapidamente nella vita politica del regno di Sardegna. Un grande lavoratore, se si considera il numero di proposte di legge da lui avanzate sia alla Camera che in Senato, anche su materie non propriamente giuridiche.

Ne costituiscono un esempio i numerosi interventi di De Foresta alla Camera a favore del mantenimento del porto franco di Nizza ${ }^{148}$ effettuati dal 1851 al 1853, che lo fecero conoscere in Parlamento ed apprezzare come un deputato preparato e capace di rappresentare efficacemente il proprio elettorato. Infatti, mentre Cavour rimaneva fermo sulle sue posizioni liberiste, che lo portavano a non consentire più ai nizzardi di avvalersi dei privilegi ereditati dal loro passato storico, perché riteneva il porto franco di Nizza una concessione ormai superata e contraria alle disposizioni dello Statuto Albertino, ma soprattutto al principio di parità dei diritti che doveva vigere all'interno di tutti i territori di uno stato costi-

\footnotetext{
${ }^{147}$ Lazzaro, 1969, p. 36 e ss.

${ }^{148}$ Cfr. Archives communales Nice, 0 62: Documents sur le port-franc de Nice et sa suppression; Riberi, 2017a; Riberi, 2017b, pp. 87-99; Mambrini, 2017; Riberi, 2019, pp. 137155
} 
tuzionale, De Foresta riuscì a rinviare per un biennio l'adozione delle misure economiche programmate dal ministro delle finanze. Per raggiungere questo scopo, il deputato nizzardo, oltre a lamentare la mancanza di efficienti vie di comunicazione ferroviarie e stradali tra il pays niçois e il resto del regno di Sardegna, evidenziò la non compensazione del danno derivante alla comunità di Nizza dalla soppressione del porto franco con idonei investimenti che risarcissero la città stessa degli introiti perduti e ne incentivassero il turismo straniero ${ }^{149}$. Ma, prima ancora di esporre queste motivazioni, De Foresta, nel corso del suo intervento sulla questione effettuato alla Camera nel 1851, dimostrò che tra l'art. 25 dello Statuto e l'atto di dedizione di Nizza al ducato di Savoia del 1388 non esisteva alcun conflitto, invitando i colleghi a

[...] riflettere che nello Statuto, mentre si dichiara che devono rispettarsi tutti i diritti, mentre si dicono inviolabili tutte le proprietà (e, a parer mio, i diritti di cui siamo in esercizio sono pur essi una proprietà) (Mormorio), non vi è neppur una parola da cui possa inferirsi che sia stata intenzione del legislatore di sopprimere senza indennità, senza compenso, i diritti derivanti dai patti deditizi, che anzi l'articolo 25 dello Statuto dice che ciascuno deve contribuire ai carichi dello Stato in proporzione dei suoi averi. Resta dunque a vedere se i diritti che risultano dai patti deditizi siano tali che distruggano questo principio $[. . .]^{150}$.

Ciò premesso la carriera di De Foresta si sviluppò in un arco di tempo abbastanza ampio: dal dicembre del 1849, quando fece il suo ingresso nel Parlamento subalpino come deputato eletto dal collegio di Nizza 1 per la IV legislatura, alla successiva rielezione nel dicembre 1853 per la $\mathrm{V}$ legislatura, alla nomina a senatore nel 1855, carica che esercitò fino al 1872, anno della sua morte.

Non mancò di tenacia soprattutto in due momenti chiave del "decennio di preparazione": quando rivesti l'impegnativa carica di ministro di Grazia e Giustizia nel 1851-1852 (dal 7 luglio 1851 al 26 febbraio 1852), durante il primo governo D'Azeglio, nei mesi in cui avveniva la svolta politica sfociata nell'alleanza Cavour-Rattazzi, e poi di nuovo dal 1855 al 1859, nel secondo governo Cavour.

La sua fu fin dagli inizi una carriera rapida: un anno e mezzo dopo la sua elezione, De Foresta - grazie alle sue competenze giuridiche e ad un'apprezzabile capacità di integrazione nella società subalpina - divenne ministro della Giustizia nel governo D'Azeglio. Come si è ricordato in questo articolo, il deputato nizzardo fu segnalato da Cavour al Presidente del Consiglio che gli affidò il ruolo di guardasigilli per sostituire Filippo Galvagno, un liberal-moderato legato al mondo della finanza e dell'industria, al quale D’Azeglio aveva fatto ricorso nei momenti più critici del suo primo Ministero (come documentato dal fatto che Galvagno fu

${ }^{149}$ Intervento di G. de Foresta, Tornata del 7 giugno 1851, in Atti del Parlamento Subalpino, Discussioni (V) 3 A, 1866, p. 2578-2581.

${ }^{150}$ Atti del Parlamento Subalpino, Discussioni (V) 3 A, 1866, pp. 2576-2577. 
predecessore e successore di De Foresta nello stesso governo) ${ }^{151}$.

Durante questo suo primo mandato De Foresta si trovò coinvolto nella stesura della legge sulla stampa, ma non fu lui ad essere il protagonista del dibattito parlamentare che, suo malgrado, si orientò, con gli interventi di Rattazzi il 4 febbraio 1852 e quello di Cavour il giorno successivo, su temi politici che dal 1850, quando le riforme promosse dal guardasigilli Siccardi avevano suscitato contrasti con la destra cattolica e conservatrice, erano oggetto dell'attenzione della Camera. Nella settimana in cui fu discusso il disegno di legge spiccano gli interventi di alcuni deputati della Destra come Balbo, Revel e Menabrea, che sostenevano posizioni più restrittive in materia di libertà di stampa, e gli interventi dei deputati di Sinistra, in particolare di Rattazzi, che le combattevano.

Ma era evidente come al di là di questo scontro si giocasse una partita politica ben più vasta e decisiva, in cui le forze in campo rappresentavano visioni già in quel momento inconciliabili. Da un lato, una parte autorevole, anche se non rilevante, della Destra continuava a pensare al futuro del regno di Sardegna in un'ottica di vecchio stampo, in cui la dinastia dei Savoia avrebbe governato ancora uno stato transnazionale, cioè i territori al di là e al di qua delle Alpi occidentali, tutelandone le diverse tradizioni, in particolare quelle religiose e linguistiche. Dall'altra c'era la visione di Cavour deciso ad avviare la sua azione politica progressista, introducendo nell'economia del regno di Sardegna riforme economiche di stampo liberista ed indirizzandolo verso l'obiettivo dell'unificazione nazionale.

Perciò alla svolta politica, maturata nel corso del dibattito della legge sulla stampa, è unanimemente riconosciuta un'importanza fondamentale nello sviluppo della vita democratica del Piemonte. Non è dunque infondato ritenere che gli effetti del 'connubio' siano andati al di là delle legislature parlamentari subalpine ed abbiano agito sul progresso generale della nazione, influendo sul superamento dei pregiudizi e dei privilegi di classe, nonché degli interessi municipalistici, e preparando sempre più il Piemonte alla sua missione italiana, secondo il disegno unitario di Cavour.

Durante il suo secondo mandato come guardasigilli, De Foresta tornò al Ministero della Giustizia per quattro anni (1855-1859), nel governo Cavour, dopo la "Crisi Calabiana", determinato a dare un contributo per migliorare il funzionamento della giustizia in generale e il sistema giudiziario in particolare, aggiornandolo alle esigenze di un società moderna sia per quanto riguarda il diritto privato che quello commerciale - come gli veniva richiesto dal primo ministro e dalla coalizione di centro-sinistra che lo sosteneva -.

Questo impegno sta all'origine delle "statistiche giudiziarie" del 1855, lavoro ancora oggi degno di attenzione e destinato a durare nel tempo.

Nel 1857 elaborò e poi concluse sette articoli destinati ad adeguare il codice penale del 1839 al nuovo regime statutario e, nel contempo, ad attribuire al giudice maggiore discrezionalità in materia di sanzione, riconoscendone l'autono-

${ }^{151}$ Romeo, II, 1977, p.568, 593 
mia dal potere politico.

In quegli stessi anni lavorò anche al testo definitivo del codice di procedura civile, che, provvisoriamente in vigore dal 1854 , doveva giungere alla sua ultima formulazione nel 1858, dopo essere stato bloccato dal Parlamento e poi adottato (in modo formalmente discutibile) dal governo La Marmora.

Infatti, dopo l'armistizio di Villafranca dell'11 luglio 1859 - che, insieme alle dimissioni di Cavour dal governo, segnò la fine della Seconda Guerra d'Indipendenza -, Rattazzi, entrato a far parte del nuovo gabinetto La Marmora come ministro dell'Interno, utilizzò la legge già sottoscritta da De Foresta il 25 aprile dello stesso anno per autorizzare l'esecutivo a promulgare leggi e decreti durante lo stato di belligeranza tra il Piemonte e l'Impero austriaco senza la necessità di farle approvare del Parlamento. Ciò consenti a Vincenzo Miglietti - subentrato al deputato nizzardo come nuovo ministro della Giustizia - di concludere l'opera di riordino amministrativo e legislativo, precedentemente avviata, riuscendo a far promulgare ben tre nuovi Codici (penale, di procedura penale, di procedura civile), che recepivano le revisioni alla codificazione "carlo-albertina" suggerite da De Foresta.

Nel '55 il giurista nizzardo, quando era necessario non cedere all'opposizione della destra conservatrice - che si stava rafforzando, mobilitando i cattolici contrari al laicismo e al giurisdizionalismo del Governo -, si pronunciò a favore del progetto di legge "sui conventi", presentato dal ministro di Grazia e Giustizia, Rattazzi, suo predecessore. In questa circostanza indubbiamente De Foresta diede un contributo alla battaglia che negli anni Cinquanta il Parlamento Subalpino combatteva per la laicizzazione dello Stato. Si disse convinto circa l'opportunità della legge, ne illustrò le caratteristiche alla luce dell'idea liberale delle diverse competenze spettanti rispettivamente al potere spirituale e a quello temporale; spiegò quanto il progetto fosse conveniente sia per il governo sia per i contribuenti, formulandone, attraverso argomentazioni afferenti al Codice civile del regno di Sardegna e allo Statuto, nonché al diritto canonico, un giudizio positivo.

Altrettanto fermamente, nel 1858, difese il progetto di legge che intendeva introdurre nuove disposizioni contro i reati di cospirazione nei confronti dei sovrani stranieri e l'apologia dell'assassinio politico, utilizzando gli strumenti della scienza penale, che conosceva a fondo, per contrastare le obiezioni degli avversari della politica di Cavour.

Il 9 giugno 1860, quando il trattato di cessione di Nizza e della Savoia giunse in Senato con il parere favorevole e quasi unanime della commissione, le voci che si levarono a motivare il loro parere contrario furono davvero poche (10 contro 92), e tra di esse molte ripeterono argomenti piuttosto triti e convenzionali. L'unica a distinguersi fu quella di De Foresta, che pronunciò un discorso pieno di amarezza e di contenuta emozione, portando una nota nuova non tanto per l'argomento - che era quello dell'italianità di Nizza - quanto per la passione con cui lo svolse, riscuotendo "applausi fragorosi e prolungati» nella commossa chiusa: 
lo qui pongo termine alle mie spiegazioni, e, come ho detto, sia carità di patria, sia dignità personale, mi obbligano a deporre contrario il mio voto nell'urna. Io non mi lusingo d'avere nella medesima molti voti compagni al mio. Fra pochi giorni il trattato sarà dunque ratificato: Nizza la città fedelissima (con molta commozione) sarà una città francese; io però non cesserò di essere italiano (Bravo!) e con voi farò voti che, come già una volta, la fedeltà, il coraggio e la costanza di Nizza salvò la Dinastia sabauda, ora il di lei sacrificio serva a condurla agli altri e finali suoi destini, e al pieno trionfo della causa italiana ${ }^{152}$.

\section{Fonti}

Archives communales Nice, 062 : Documents sur le port-franc de Nice et sa suppression

Archivio di Stato di Torino, Sezioni Riunite: Archivio Savio, cartella n. 356, 25/30 Atti del Parlamento Subalpino - Discussioni della Camera dei Deputati, IV Legislatura - Sessione 1851 (23/11/1850 - 27/02/1852), volume (V) 3A delle discussioni della camera dei deputati dal 22/03/1851 al 19/05/1851, 1866: Firenze, Eredi Botta

Atti del Parlamento Subalpino - Discussioni della Camera dei Deputati, IV Legislatura - Sessione 1851 (23/11/1850 - 27/02/1852), volume (VIII) 6A delle discussioni della camera dei deputati dal 19/01/1852 al 27/02/1852, 1866: Firenze, Eredi Botta

Atti del Parlamento Subalpino - Sessione 1851 dal 23 novembre 1850 al 27 febbraio 1852 (IV Legislatura), Documenti, volume II, 1865: Torino, Eredi Botta Atti del Parlamento Subalpino - Discussioni della Camera dei Deputati, IV Legislatura - Sessione 1852 (04/03/1852 - 21/11/1853), volume (VII) 4A delle discussioni della camera dei deputati dal 12/02/1853 al 22/04/1853, 1868: Firenze, Eredi Botta

Atti del Parlamento Subalpino - Discussioni della Camera dei Deputati, V Legislatura - Sessione 1853-1854 (19/12/1853 - 29/05/1855), volume (VI) 3A delle discussioni della camera dei deputati dal 28/11/1854 al 03/03/1855, 1870: Firenze, Eredi Botta

Atti del Parlamento Subalpino - Discussioni della Camera dei Deputati, V Legislatura - Sessione 1853-1854 (19/12/1853 - 29/05/1855), volume (VII) 4A delle discussioni della camera dei deputati dal 05/03/1855 al 29/05/1855, 1870: Firenze, Eredi Botta

Atti del Parlamento Subalpino, Sessione del 1853-1854 (V Legislatura), dal 19 dicembre 1853 al 29 maggio 1855, Documenti, volume II, 1869: Firenze, Eredi Botta

152 Atti del Parlamento Italiano, Sessione del 1860 (VII Legislatura) dal 2 aprile al 28 dicembre 1860, volume IV Unico delle Discussioni del Senato del Regno, 1875: p. 100. 
Atti del Parlamento Subalpino, Sessione del 1853 -1854 (V Legislatura), dal 19 dicembre1853 al 29 maggio1855, Documenti, volume III, 1869: Firenze, Eredi Botta

Atti del Parlamento Subalpino - Discussioni della Camera dei Deputati, V Legislatura - Sessione 1855-1856 (12/11/1855 - 16/06/1856), volume (IV) 2A delle discussioni della camera dei deputati dal 17/03/1856 al 16/06/1856, 1872: Roma, Eredi Botta

Atti del Parlamento Subalpino - Discussioni della Camera dei Deputati, V Legislatura - Sessione 1857 (07/01/1857 - 16/07/1857), volume (IV) 2A delle discussioni della camera dei deputati dal 14/03/1857 al 19/05/1857, 1873: Roma, Eredi Botta

Atti del Parlamento Subalpino, Sessione 1857 (V Legislatura) dal 7 gennaio al 16 Iuglio 1857, Documenti, volume I, 1872: Roma, Eredi Botta

Atti del Parlamento Subalpino - Discussioni della Camera dei Deputati, VI Legislatura - Sessione 1857-1858 (14/12/1857 - 14/07/1858), volume (III) 1A delle discussioni della camera dei deputati dal 14/12/1857 al 24/03/1858 1874: Roma, Eredi Botta

Atti del Parlamento Subalpino - Discussioni della Camera dei Deputati, VI Legislatura - Sessione 1857-1858 (14/12/1857 - 14/07/1858), volume (IV) 2A delle discussioni della camera dei deputati dal 23/03/1858 al 31/05/1858, 1874: Roma, Eredi Botta

Atti del Parlamento Subalpino, Sessione del 1857-1858 dal 14 dicembre 1857 al 14 luglio 1858, Documenti, volume I, 1873: Roma, Eredi Botta

Atti del Parlamento Subalpino - Discussioni della Camera dei Deputati, VI Legislatura - Sessione 1859 (10/01/1859 - 30/04/1859), volume (III) Unico delle discussioni della camera dei deputati dal 10/01/1859 al 30/04/1859, 1875: Roma, Eredi Botta

Atti del Parlamento subalpino, Sessione del 1859 (VI Legislatura), dal 10 gennaio al 30 maggio 1859, Documenti, volume II, 1875: Roma, Eredi Botta

Atti del Parlamento Italiano, Sessione del 1860 (VII Legislatura), dal 2 aprile al 28 dicembre 1860, volume IV Unico delle Discussioni del Senato del Regno, 1875: Roma, Eredi Botta

Bulletin des lois du Royaume de France, VIle Série, Tome VIII, 1819 : Paris, Imprimerie royale, B. $\mathrm{n}^{\circ} 278$

Bulletin des lois du Royaume de France, IXe Série, Ire Partie, Tome VII, 1835: Paris, Imprimerie royale 1835, B. ${ }^{\circ} 155$

Codice civile per gli Stati di S. M. il Re di Sardegna, 1837: Torino, Stamperia reale Codice penale per gli Stati di S.M. il Re di Sardegna, 1839: Torino, Stamperia reale Raccolta degli Atti del Governo di S. M. il Re di Sardegna, vol. XVI, Dal $1^{\circ}$ gennaio 
a tutto dicembre 1848, s.d.: Torino, Stamperia reale

Raccolta degli Atti del Governo di S. M. il Re di Sardegna, vol. XX, dal $1^{\circ}$ gennaio a tutto dicembre 1852, s.d.: Torino, Stamperia Reale, http://www.dircost.unito. it/root_subalp/1852.shtml

Raccolta degli Atti del Governo di Sua Maestà il Re di Sardegna, volume XXIII, Anno $1854-2^{\circ}$ semestre dal 30 giugno a tutto dicembre, s.d.: Torino, Stamperia Reale

Raccolta degli Atti del Governo di Sua Maestà il Re di Sardegna, volume XXIV, anno 1855, s.d.: Torino, Stamperia reale

Raccolta degli Atti del Governo di Sua Maestà il Re di Sardegna, volume XXVII, Anno 1858, s.d.: Torino, Stamperia reale

Raccolta degli Atti del Governo di Sua Maestà il Re di Sardegna, volume XXVIII, Anno 1859, s.d.: Torino, Stamperia reale

Statistica giudiziaria civile, commerciale e del contenzioso amministrativo degli Stati sardi per gli anni 1849 - 1850, 1852: Torino, Eredi Botta

\section{Bibliografia}

Aimerito F., 2008: La codificazione della procedura civile nel regno di Sardegna, Milano, Giuffrè

Albano F., 2017: Cento anni di padri della patria 1848-1948, Roma, Carocci

Apeciti E., 2013: «Nazari di Calabiana, Luigi», in Dizionario Biografico degli Italiani, vol. 78, Roma, Treccani, pp. 63-66

Balduzzi R., Ghiringhelli R., Malandrino C. (eds.) 2009: L'altro Piemonte e I'Italia nell'età di Urbano Rattazzi (1808-1873), Padova, Cedam

Barelli H., Rocca R., 1995: Histoire de l'identité niçoise, Nice, Serre

Bartolotta F., 1971: Parlamenti e Governi d'Italia dal 1848 al 1970, vol. 2, Roma, Vito Bianco Editore

Berthier B., 2016: II plebiscito del 1860 in Savoia, in G.S. Pene Vidari (ed.), I plebisciti del 1860 e il governo sabaudo, Torino, Deputazione Subalpina di storia patria, pp. 217-221

Bianchi P., Merlotti A., 2017: Storia degli Stati sabaudi (1416-1848), Brescia, Morcelliana

Borelli F., 1989: Cronache di Rosa Vercellana contessa di Mirafiori, Firenze, Firenze libri

Bottasso E., 1972: «Brofferio, Angelo», in Dizionario Biografico degli Italiani, vol. 14, Roma, Treccani, pp. 408-413

Briano G., 1857: I ministri e la loro particolare istoria, Giovanni De Foresta e Pietro Paleocapa, Torino, Tipografia subalpina 
Cafagna L., 1999: Cavour, Bologna, II Mulino

Campobello F., 2015: Gli enti ecclesiastici nell'Italia liberale: strategie politiche e normativa tra 'escalation' e tentativi di 'riconciliazione', in "Stato, Chiese e pluralismo confessionale, Rivista telematica" (www.statoechiese.it), n 15

Cappa A., 1932: Cavour, Bari, Editori Laterza

Caracciolo A., 1972: Il Parlamento nella formazione del Regno d'Italia, Milano, Giuffrè

Carteggio Cavour-Nigra dal 1858 al 1861 1929: 4 volumi, Bologna, Zanichelli, 1929

Casana P., 1997: «Ferrero Della Marmora, Alfonso», in Dizionario Biografico degli Italiani, vol. 47, Roma, Treccani, pp. 44-47

Casana P., 2001: Metamorfosi di un accordo: la questione di Nizza e Savoia nel quadro politico-istituzionale dell'unificazione, in F. Peirone, Per Torino da Nizza e Savoia. Le opzioni del 1860 per la cittadinanza torinese da un Fondo dell'Archivio Storico della Città di Torino, G.S. Pene Vidari e R. Roccia (eds.), Torino, Centro studi piemontesi, pp. 11-31

Casana P., 2010: La prima fase dell'unificazione italiana: trattati e trattative diplomatiche, in G.S. Pene Vidari (ed.), Verso I'unità italiana. Contributi storicogiuridici, Torino, Giappichelli, pp. 81-104

Casana P., 2012: Gli «strumenti» del Risorgimento nazionale. Accordi, trattati, plebisciti, personaggi, Giappichelli, Torino

Casana P., 2013: Un costituzionalista al servizio dello Stato: Carlo Bon-Compagni di Mombello e l'unificazione italiana, in C.S. Roero (ed.) Dall'Università di Torino all'Italia unita. Contributi dei docenti al Risorgimento ed all'Unità, Torino, Deputazione Subalpina di storia patria, pp. 59-96

Casana P., 2016a: I trattati franco-subalpini tra il 1858 e il 1860, in G.S. Pene Vidari (ed.), I plebisciti del 1860 e il governo sabaudo, Torino, Deputazione Subalpina di storia patria, pp. 51-71

Casana P., 2016b: Il quadro politico-istituzionale (aprile 1860 - febbraio 1861), in G.S. Pene Vidari (ed.), I plebisciti del 1860 e il governo sabaudo, Torino, Deputazione Subalpina di storia patria, pp. 239-250

Casana P., 2020: L'educazione del principe. L'assetto dell'amministrazione sabauda in un documento del XIX secolo, Torino, Giappichelli

Cassetti M., Silengo G. (eds.), 1978: Alfonso Ferrero Della Marmora e il suo tempo, Catalogo della mostra documentaria, Biella, Archivio di Stato di Biella

Cavicchioli S., 2004: Famiglia, memoria, mito. I Ferrero Della Marmora (17481918), Roma, Carocci

Cavour C., 1962-2012 : Epistolario, volumi I-XXI, eds. Carlo Pischedda e Rosanna Roccia, Firenze, Olshki 
Cavour C., 1984: Epistolario, volume IX (1852), eds. Carlo Pischedda e Rosanna Roccia, Firenze, Olschki

Cernigliaro A., 2016: La brochure parigina di Massimo d'Azeglio, in G.S. Pene Vidari (ed.), I plebisciti del 1860 e il governo sabaudo, Torino, Deputazione Subalpina di storia patria, pp. 71-88.

Chiala L. (ed.), 1886: I/ conte di Cavour. Ricordi di Michelangelo Castelli, TorinoNapoli, Roux e Favale

Cognasso F. (ed.), 1966: Le lettere di Vittorio Emanuele II, Torino, Deputazione Subalpina di storia patria, 2 voll.

Compan A., 1973: Histoire de Nice et de son comté, Toulon, L’astrado

D’Addio M., 1966: Politica e magistratura (1848-1876), Milano, Giuffrè

D’Addio M., Ghisalberti C., Lanchester F., Negri G., Perfetti F., Sofia F., Tentoni L. (eds.), 1994: Le grandi leggi elettorali italiane 1848 - 1993, Roma, Colombo

Dansette A., 1964: L'attentat d'Orsini, Paris, Del Duca

De la Rive W., 1862-1863 : Le comte de Cavour, récits et souvenirs, Paris, J. Hetzel, trad. it., Torino, Bocca, 1911 (nuov. ed. Milano, Rizzoli, 1951)

Della Volpe G., 1932: voce «Franchi, Ausonio», in Enciclopedia Italiana, http:// www.treccani.it/enciclopedia/ausonio-franchi_\%28Enciclopedia-Italiana\%29/

Dezza E., 2009: "Il colpo di Stato legislativo" del 1859 e la nascita del codice Rattazzi, in S. Vinciguerra (ed.), II Codice penale per gli Stati del Re di Sardegna e per I'Italia Unita (1859), Padova, Cedam, pp. IX-XXXII

Dionisotti C., 1881: Storia della magistratura piemontese, vol. II, Torino, Roux e Favale

Ferrero I., 2016: La Facoltà legale di Torino ed iprogettidi riforma dell'insegnamento universitario nel Regno di Sardegna risorgimentale, in "Rivista di Storia dell'Università di Torino", V, nº 1

Ford F. L., 1990 : Le meurtre politique: du tyrannicide au terrorisme, Paris, P.U.F.

Franzoni Gamberini L., 1972: «Buffa, Domenico», in Dizionario Biografico degli Italiani, vol. 14, Roma, Treccani, pp. 803-806

Gandolfo A., 2011: La cessione di Nizza e della Savoia alla Francia nel 1860, in "Rivista dell'Istituto storico della Resistenza e della società contemporanea in provincia di Cuneo", n79, pp. 107-160

Genta E., 2001: Principio dinastico e principio di nazionalità nell'800: aspetti diplomatici e giuridici relativi alla cessione di Nizza e Savoia, in F. Peirone, Per Torino da Nizza e Savoia. Le opzioni del 1860 per la cittadinanza torinese da un Fondo dell'Archivio Storico della Città di Torino, G. S. Pene Vidari e R.Roccia (eds.), Torino, Centro studi piemontesi, pp. 34-43.

Genta E., 2016: Prospettive istituzionali ed internazionali per I'inserimento sabaudo nell'Italia centrale, in G. S. Pene Vidari (ed.), I plebisciti del 1860 e il 
governo sabaudo, Torino, Deputazione Subalpina di storia patria, pp. 89- 107

Gentile P., 2017: L'ombra del re. Vittorio Emanuele II e le politiche di corte, Roma, Carocci

Gentile P. (ed.), 2018: Camillo Cavour. Una biografia per immagini, Santena, Fondazione Cavour

Gonnet P., 2003: La réunion de Nice à la France, Breil sur Roya, Éditions du Cabri

Guichonnet P., 1961: Cavour agronomo e uomo d'affari, Milano, Feltrinelli

Guichonnet P., 2003: Comment Nice devint française, in Histoire de l'annexion de la Savoie à la France, Montmélian, La Fontaine de Siloé, pp. 317-329

Hearder H., 1994: Cavour, London, Longman, 1994, trad. it. Cavour, un europeo piemontese, Roma-Bari, Laterza, 2000

Jemolo A.C., 1935: voce "Quota di concorso» in Enciclopedia Italiana, http://www. treccani.it/enciclopedia/quota-di-concorso_\%28Enciclopedia-Italiana\%29

Latouche R., 1954: Histoire de Nice, tome II, 1860-1914, Nice, Ville de Nice

Lazzaro G., 1969: La libertà di stampa in Italia dall'Editto Albertino alle norme vigenti, Milano, Mursia

Le carte di Giovanni Lanza, 1938: ed. Regia Deputazione Subalpina di storia patria, I, Deputazione Subalpina di storia patria, Casale Monferrato

Levra U. (ed.), 2011, Cavour, I'Italia e l'Europa, Bologna, il Mulino

Levra U., 1992: Fare gli Italiani. Memoria e celebrazione del Risorgimento, Torino, Comitato di Torino dell'Istituto per la storia del Risorgimento italiano

Louessard L., 2000: L'épopée des régicides: passions et drames, 1814-1848, Montreuil, L'Insomniaque

Mack Smith D., 1958: Cavour e Garibaldi nel 1860, Torino, Einaudi

Mack Smith D., 1968: Vittorio Emanuele, Cavour e il Risorgimento, Bari, Laterza

Mack Smith D., 1972: Vittorio Emanuele II, Bari, Laterza

Mack Smith D., 1985: Cavour, London, Methuen

Mack Smith D., 1990: I Savoia re d'Italia, Milano, Rizzoli

Mack Smith D., 1999: Cavour contro Garibaldi, Milano, Rizzoli

Malandrino C., 2014: Lineamenti del pensiero politico di Urbano Rattazzi: unità nazionale, costituzione e laicità dello Stato, temperato progresso, Milano, Giuffrè

Malandrino C., 2016: «Rattazzi, Urbano», in Dizionario Biografico degli Italiani, vol. 86, Roma, Treccani, pp. 558-562

Mambrini C., 2017: Ricerche storico-giuridiche sul porto franco di Nizza, tesi magistrale, Dipartimento di Giurisprudenza, Università degli Studi di Torino

Martone L., 1978: «Cassinis, Giovanni Battista», in Dizionario Biografico degli 
Italiani, vol. 21, Roma, Treccani, http://www.treccani. it/enciclopedia/giovannibattista-cassinis_(dizionario-biografico)/

Marucco D., 1996: L'amministrazione della statistica nell'Italia unita, Roma-Bari, Laterza

Maturi W., 1962: «Azeglio, Massimo Taparelli d'», in Dizionario Biografico degli Italiani, vol. 4, Roma, Treccani, pp.746-756

Milbach S. (ed.), 2012: 1860, la Savoie, la France et l'Europe, Actes du colloque de I'Université de Savoie, 2010, Bruxelles, Peter Lang

Molfese F., 1974: Storia del brigantaggio dopo I'Unità, Milano, Feltrinelli

Mongiano E., 2003: Il voto della nazione. I plebisciti nella formazione del Regno d'Italia (1848-60), Torino, Giappichelli

Mongiano E., 2016: I plebisciti meridionali, umbro e marchigiano, in G.S. Pene Vidari (ed.), I plebisciti del 1860 e il governo sabaudo, Torino, Deputazione Subalpina di storia patria, pp. 355-374

Montaldo S., 2016: Dall'armistizio di Villafranca ai plebisciti di marzo e aprile del 1860, in G.S. Pene Vidari (ed.), I plebisciti del 1860 e il governo sabaudo, Torino, Deputazione Subalpina di storia patria, pp. 13-21

Oliva G., 1999: I Savoia. Novecento anni di una dinastia, Milano, Mondadori

Omodeo A., 1940: L'opera politica del conte di Cavour, Parte I (1848-1857), volumi I-II, Firenze, La Nuova Italia (nouva ed. Milano, Mursia, 1968-2012)

Ortolani M., Berthier B. (eds.), 2013: Consentement des populations, plébiscites et changements de souveraineté en Europe occidentale de la révolution à la première guerre mondiale, Nice, Serre

Ortolani M., 2016: Le plébiscite de 1860 pour l'annexion de Nice à la France, in G.S. Pene Vidari (ed.), I plebisciti del 1860 e il governo sabaudo, Torino, Deputazione Subalpina di storia patria, pp. 187-216

Panzini A., 1932: Cavour et l'épopée du Risorgimento, Paris, Payot

Passerin d'Entrèves E., 1979: "Cavour, Camillo Benso conte di», in Dizionario Biografico degli Italiani, vol. 23, Roma, Treccani, pp. 120-138

Passerin d'Entrèves E., 1956: L'ultima battaglia politica di Cavour: i problemi dell'unificazione italiana, Torino, ILTE

Pene Vidari G.S., 2013: Prospettive e contributi della Facoltà giuridica, in C.S. Roero (ed.), Dall'Università di Torino all'Italia unita. Contributi dei docenti al Risorgimento ed all'Unità, Torino, Deputazione Subalpina di storia patria, pp. 1-58

Pene Vidari G.S., 2016: Accordi diplomatici e consenso popolare. I plebisciti del marzo 1860, in G.S. Pene Vidari (ed.), I plebisciti del 1860 e il governo sabaudo, Torino, Deputazione Subalpina di storia patria, pp. 109-123

Pene Vidari G.S., 2019: I/ Proclama di Moncalieri, in A. Malerba, A. Merlotti, G. 
Mola Di Nomaglio, M.C. Visconti (eds.), Il Castello di Moncalieri. Una presenza sabauda fra Corte e Città, Torino, Centro studi piemontesi, pp. 225-238

Pene Vidari G.S., 2020: Note sul proclama di Moncalieri dell'autunno 1849, in "Rivista di storia del diritto italiano», vol. 93, 2, pp. 332-345

Pischedda C., 2004: Pagine sul Risorgimento, ed. R. Roccia, Santena, Fondazione Cavour

Procès de Orsini, de Rudio, Gomez, Pierri et Bernard : attentat du 14 janvier 1858 contre la vie de S.M. Napoléon III, Empereur des français, Triple condamnation à mort, Cour d'Assises de la Seine - Audience de 25 et 26 Février 1858, 185 : Brienne, G. Martin.

Rattazzi U., 2013: Epistolario, ed. R. Roccia, 2 voll., Roma, Gangemi

Ratti G., 1987: "De Foresta, Giovanni», in Dizionario Biografico degli Italiani, vol. 33, Roma, Treccani, pp. 792-794

Riberi M., 2017a: I deputati nizzardi e savoiardi al parlamento subalpino: le 'petites patries' tra nuovo diritto pubblico europeo e principio di nazionalità, in "Italian Review of Legal History", n. 3

Riberi M., 2017b: Les franchises face au Statut Albertin. La fin du port franc de Nice, in "Nice historique ", n. 120, pp. 87-99

Riberi M., 2019 : Les députés du pays niçois à la Chambre subalpine de Turin (1848-1860). Un itinéraire historique et juridique, eds. M. Ortolani et O. Vernier. Avant-propos de M. Bottin, Préface de G. S. Pene Vidari, Nice, Aspeam, Serre

Riberi M., 2020 : La creazione giuridica del Regno d'Italia, Torino, Giappichelli

Ricci S., De Luca G., Bertola A., 1936: «Stola», in Enciclopedia Italiana, http:// www.treccani.it/enciclopedia/stola_\%28Enciclopedia-Italiana\%29/

Roccia R., 2016: I plebisciti della primavera 1860 nel dialogo a più voci dell'Epistolario cavouriano, in G.S. Pene Vidari (ed.), I plebisciti del 1860 e il governo sabaudo, Torino, Deputazione Subalpina di storia patria, pp. 123-140

Romeo R., 1959: /l Piemonte della Restaurazione e la giovinezza di Cavour, Messina, Ferrara editore

Romeo R., 1969: Cavour e il suo tempo, volume I (1810-1842), Roma-Bari, Laterza

Romeo R., 1977: Cavour e il suo tempo, volume II (1842-1854), Roma- Bari, Laterza

Romeo R., 1984: Cavour e il suo tempo, volume III (1854-1861), Roma- Bari, Laterza

Romeo R., 1984: Vita di Cavour, Roma- Bari, Laterza

Ruggiero A. (ed.), 2006: Nouvelle histoire de Nice, Toulouse, Éd. Privat

Sappia H., 1903: Les Cessolines ou I'hospice de la Providence, in "Nice Historique", pp. 55-58 e 73-80

Sardo G., 1966: Storia del Parlamento italiano, diretta da N. Rodolico, vol. III, 


\section{Palermo, Flaccovio}

Sardo G., 1966: Storia del parlamento italiano, diretta da N. Rodolico, vol. IV, Palermo, Flaccovio

Savio C.F., 1939: Luigi Nazari, dei conti di Calabiana, arcivescovo di Milano, cavaliere della Ss. Annunziata, senatore del Regno, Torino, Casanova

Scaparone M., 2012: L'ordinamento giudiziario, Torino, Giappichelli

Schor R., Courrière H. (eds.), 2011: Le comté de Nice, la France et l'Italie. Regards sur le rattachement de 1860, Nice, Serre

Soffietti I., 2009: La legge Rattazzi di soppressione di alcune corporazioni religiose, in R. Balduzzi, R. Ghiringhelli, C. Malandrino (ed.) L'altro Piemonte e I'Italia nell'età di Urbano Rattazzi (1808-1873), Padova, Cedam, pp. 293-302

Soffietti I., 2016: Una testimonianza di parte napoleonica sulle vicende italiane del 1859-60. Un memoriale del maresciallo di Francia Jean-Baptiste-Philibert Vaillant, in G.S. Pene Vidari (ed.), I plebisciti del 1860 e il governo sabaudo, Torino, Deputazione Subalpina di storia patria, pp. 23-49

Solimano S., 2003: Il letto di Procuste. Diritto e politica nella formazione del Codice civile unitario. I progetti Cassinis (1860-1861), Milano, Giuffrè

Solimano S., 2013a: "Cassinis Giovanni Battista», in Dizionario biografico dei giuristi italiani (XII-XX secolo), ed. E. Cortese, I. Birocchi, A. Mattone, M.N.Miletti, Bologna, II Mulino, pp. 481-482

Solimano S., 2013b: II contributo dei civilisti all'edificazione del codice civile unitario (1848-1865), in "Rivista italiana per le Scienze giuridiche", 4, pp. 386387.

Sorrel Ch., 2010: Comment la Savoie et Nice sont devenues françaises, in "L'Histoire", n 351, pp. 8-15

Talamo G., 2010: Cavour. Studio biografico sulla vita e le opere di Camillo Benso, Roma, Gangemi

Tombaccini S., 2009: Notes sur les sources d'archives publiques et privées pour I'histoire de liannexion du comté de Nice in Aux sources de l'histoire de l'annexion de la Savoie, ed. D. Varaschin, Bruxelles, Peter Lang, pp. 91-99

Traniello F., 1969: «Bon Compagni di Mombello, Carlo», in Dizionario Biografico degli Italiani, vol. 11, Roma, Treccani, pp. 695-703

Traverso M., 2019a : Fo dire al Re che... Massimo d'Azeglio e la prima crisi costituzionale subalpina, in E. Genta, D. De Franco, A. Pennini (eds.), "Une très ancienne famille piémontaise". I Taparelli negli Stati sabaudi (XVII-XIX secolo), Milano, Ledizioni, pp. 161-178.

Traverso M., 2019b: La grassazione e i reati contro la proprietà nei codici sabaudi e post-unitari, in "Rivista di storia del diritto italiano", n ${ }^{\circ}$ XCI-1, pp. 293-327

Vernier O., 1990 : Nice et la représentation parlementaire de son comté à 
Turin 1848-1860, in «Recherches régionales, Alpes maritimes et contrées limitrophes», 2, pp. 70-75

Vernier O., 1993 : D'espoir et d'espérance. L'assistance privée dans les AlpesMaritimes au XIXe siècle, Nice, Serre

Vernier O., 2009: Comté de Nice, in La Savoie et l'Europe 1860-2010-Dictionnaire historique de l'annexion, Montmélian, La fontaine de Siloé, pp. 345-349

Viarengo A. (ed.), 2010: Camillo Cavour. Autoritratto. Lettere, diari, scritti e discorsi, Milano, Rizzoli

Viarengo A., 2010: Cavour, Roma, Salerno editrice

Viarengo A., 2017: Vittorio Emanuele II, Roma, Salerno editrice 
